\title{
Hybrid Thin-Film Materials Combinations for Complementary Integration Circuit Implementation
}

\author{
Gunhoo Woo ${ }^{1}$, Hocheon Yoo ${ }^{2, *(1)}$ and Taesung Kim ${ }^{1,3, *}$ \\ 1 SKKU Advanced Institute of Nanotechnology, Sungkyunkwan University (SKKU), Suwon 16419, Korea; \\ dnwhddms12@skku.edu \\ 2 Department of Electronic Engineering, Gachon University, Seongnam 13120, Korea \\ 3 Department of Mechanical Engineering, Sungkyunkwan University (SKKU), Suwon 16419, Korea \\ * Correspondence: hyoo@gachon.ac.kr (H.Y.); tkim@skku.edu (T.K.)
}

Citation: Woo, G.; Yoo, H.; Kim, T. Hybrid Thin-Film Materials Combinations for Complementary Integration Circuit Implementation. Membranes 2021, 11, 931. https:// doi.org/10.3390/membranes11120931

Academic Editor: Feng-Tso Chien

Received: 28 October 2021

Accepted: 22 November 2021

Published: 26 November 2021

Publisher's Note: MDPI stays neutral with regard to jurisdictional claims in published maps and institutional affiliations.

Copyright: (c) 2021 by the authors. Licensee MDPI, Basel, Switzerland. This article is an open access article distributed under the terms and conditions of the Creative Commons Attribution (CC BY) license (https:// creativecommons.org/licenses/by/ $4.0 /)$.

\begin{abstract}
Beyond conventional silicon, emerging semiconductor materials have been actively investigated for the development of integrated circuits (ICs). Considerable effort has been put into implementing complementary circuits using non-silicon emerging materials, such as organic semiconductors, carbon nanotubes, metal oxides, transition metal dichalcogenides, and perovskites. Whereas shortcomings of each candidate semiconductor limit the development of complementary ICs, an approach of hybrid materials is considered as a new solution to the complementary integration process. This article revisits recent advances in hybrid-material combination-based complementary circuits. This review summarizes the strong and weak points of the respective candidates, focusing on their complementary circuit integrations. We also discuss the opportunities and challenges presented by the prospect of hybrid integration.
\end{abstract}

Keywords: complementary inverter; thin-film transistors; material integration; organic semiconductors; metal oxides

\section{Introduction}

Over the past few decades, silicon-based transistor technology has been dominant in the electronics industry because of the excellent electrical characteristics and scaling technology, whereas the limitations of the fabrication process restricted large-scale fabrication and use on flexible substrates [1,2]. Thin-film transistors (TFTs) have been extensively developed with great significance for large-area electronics [3-5]. Due to manufacturing advantages, TFTs can be fabricated on a variety of substrates such as flexible plastics [6-8], banknotes [9], skin [10,11], and even textiles [12-14]. Various TFTs are being explored, targeting flexible (or stretchable) displays $[15,16]$, functional photo- $[17,18]$, gas- $[19,20]$, and bio-sensors $[21,22]$, and healthcare electronics $[23,24]$ as potential applications.

In TFTs, the semiconductor material usually determines the operational type (i.e., $p$-type or $n$-type), where $p$-type TFTs operate via negative gate-source voltage bias when using materials known as $p$-type semiconductors, such as dinaphtho [2,3-b:2', $3^{\prime}$-f] thieno[3,2b] thiophene (DNTT) [25-27], cupric oxide (CuO) [28-30], carbon nanotubes [31-34], and emerging perovskite materials [35-37]. In contrast, $n$-type TFTs operate via positive gate-source voltage bias based on materials known as $n$-type semiconductors, such as molybdenum disulfide $\left(\mathrm{MoS}_{2}\right)$ [38-40], indium gallium zinc oxide (IGZO) [41-43], and $\mathrm{N}, \mathrm{N}^{\prime}$ ditridecylperylene-3,4,9,10-tetracarboxylic diimide (PTCDI-C13) [44,45]. As noted and listed above, fabrication process combinations of different materials are required to build complementary circuitry, composed of the respective $p$-type and $n$-type TFTs.

A complementary metal oxide semiconductor (CMOS) is based on a field-effect transistor (FET) manufacturing process that uses complementary and symmetric pairs of $p$-type and $n$-type FETs. CMOS is built with a combination of a $p$-type transistor and an n-type transistor, and switching the on/off state of the $p-/ n$-transistor along with sweeping the 
input voltage produces a change in the signal corresponding to " 0 " and " 1 " states. A CMOS inverter circuit has the $n$ - $/ p$-transistors connected to drain and gate electrodes, a supply voltage $\left(\mathrm{V}_{\mathrm{DD}}\right)$ to the pull-up $p$-transistor, and ground $(0 \mathrm{~V})$ connected to the pull-down $p$-transistor. The performance of a CMOS inverter is determined by the following parameters: (1) voltage gain, (2) noise margin (the amount of the noise of the output voltage that is affordable to withstand the operation failure), and (3) power consumption. Since the symmetrically matched $I_{D}-V_{D}$ curve of an $n-/ p$ - transistor can accompany the excellent inverter behavior, modulating the shape of the $I_{D}-V_{D}$ curve of each transistor is the crucial factor. Furthermore, introduction of a high-k dielectric layer is useful to reduce the power consumption by reducing the operation input voltage range [46].

For complementary technology, as a general approach, transistors are made using the same material family, i.e., small molecules, polymers, oxides, and transition metal dichalcogenides (TMDs). Another approach was attempted by implementing complementary transistors using more than one different material family. Implementing complementary behavior using these heterogeneous materials makes a hybrid complementary TFT. This hybrid complementary approach offers advantages that compensate for the disadvantages of each family of materials. Low temperature polysilicon oxide (LTPO) CMOS is proper example to explain the possibility of a hybrid CMOS inverter. The combination of the high mobility property from a $p$-channel low temperature polysilicon (LTPS) TFT and the low off-current property from an $n$-channel $a$-IGZO TFT led to enhanced device performance [47]. Furthermore, the hybrid materials combination approach can accompany the simplification of the fabrication process. For example, polymer-based patterning processes are mainly conducted to modify the dimension of TMD materials, causing defects during the etching process or material contamination. In contrast, metal oxide or organic materials are simply patterned with a shadow mask or inkjet printing method, which reduces the complex patterning process [48].

In this context, we summarize here the recent progress in the development of hybrid complementary TFTs. This review is motivated by the emergence of various thin-film semiconducting materials enabling next-generation functionality in TFTs. This review provides an overview of the recent contributions to hybrid complementary integrations using emerging TFT materials: (1) 2D TMDs, (2) metal oxides, (3) organic semiconductors, (4) perovskite materials, and (5) carbon nanotubes. Furthermore, we introduce a newly investigated approach to heterogenous hybrid TFTs, presenting novel applications to multi-valued logics and vertically stacked inverters.

\section{Materials for Hybrid Inverters}

\subsection{Two-Dimensional Transition Metal Dichalcogenides Materials}

Two-dimensional (2D) TMD material comprises multiple stacked layers with thicknesses in sub-nanometers [49-51]. The 2D structure aligns the electron transportation to the plane while constraining the Z-axial direction, and each layer is coupled by a weak van der Waals (vdWs) force. The structural specificity produces superior electrical and optical properties, and induces a sharp contact condition with other materials [52,53]. Moreover, because of their excellent mechanical properties such as flexibility and rigidity, 2D materials have attracted a lot of attention as potential candidates for various applications such as field-effect transistors (FET) [54,55], gas sensors [56], photo sensors [57,58] and flexible or ubiquitous substrates $[59,60]$. The information of electrical properties and structure dimension of 2D TMD materials was tabulated in Table 1. However, preparation of the high-quality TMD materials for large-scale applications is still limited because of obvious pros and cons for each method: (1) Exfoliation (pros-easy-to-fabricate process, cons-only for flake-scale device), (2) hydrothermal synthesis (pros-mild synthesis condition and layer-scale film, cons-low uniformity), and CVD growth (pros-good quality material with large-scale, cons-limitations in usage flexible substrate) [61,62]. In 2015, Lee et al. reported a hybrid CMOS logic inverter that is built with a top gate $n-\mathrm{MoS}_{2}$ nanosheet and a bottom gate $p$-heptazole FET [63]. To match the $I_{D}-V_{D}$ curve of the $n$-channel $\mathrm{MoS}_{2}$ 
FET symmetrically to that of the $p$-channel heptazole FET, the threshold voltage, mobility, and drain current level were modified by controlling the thickness of the $\mathrm{MoS}_{2}$ layer and inserting a CYTOP buffer layer between the $\mathrm{MoS}_{2}$ and insulate layers (Figure 1a). The fabricated organic-inorganic hybrid inverter exhibited a significant voltage gain of $12 \mathrm{v} / \mathrm{v}$ at a supplied voltage of $5 \mathrm{~V}$ with only a few hundred picowatts $(\mathrm{pW})$ in power consumption (Figure 1b). In 2017, Lee et al. fabricated a 2D nanosheet-oxide film hybrid inverter comprising a $p$-channel $\mathrm{MoTe}_{2}$ FET and an $n$-channel IGZO FET, as shown in Figure 1c [64]. By using a 2D TMD semiconductor that possesses favorable optical and electrical properties for inverter applications, the author achieved significant voltage gain as high as $40 \mathrm{v} / \mathrm{v}$ at a drain voltage of $5 \mathrm{~V}$ with only a few nanowatts $(\mathrm{nW})$ in scale power consumption. In 2016, Das et al. reported a highly flexible and large-scale $\mathrm{Si}-\mathrm{MoS}_{2}$ hybridcomplementary inverter combining an $n$-channel $\mathrm{MoS}_{2}$ FET and a $p$-channel Si nanomembrane (NM) FET [65]. By transferring the CVD-grown $\mathrm{MoS}_{2}$ and the Si NM, which showed proper flexibility on a flexible polyimide substrate, a bendable Si-MoS ${ }_{2}$ hybrid complementary inverter was implemented (Figure 1d). The voltage transfer curve of the $n-\mathrm{MoS}_{2}$ and $p$-Si NM hybrid inverter showed a voltage gain of $12 v / v$ at a $5 \mathrm{~V}$ supply voltage with low power consumption of $100 \mathrm{nW}$. In addition, the performance of the flexible hybrid inverter was maintained under bending situations. During the variation of the bending radius $(3.2 \mathrm{~nm}, 4.0 \mathrm{~nm}$, $5.4 \mathrm{~nm}, 6.2 \mathrm{~nm}$, flat), the maximum voltage gain and threshold voltage were $10.75 \pm 2 \mathrm{v} / \mathrm{v}$ and $2.34 \pm 0.30 \mathrm{~V}$, respectively. The normalized voltage gain within $5 \%$ and $20 \%$ and high consistency of the threshold voltage during 100 bending cycles showed the performance reliability of the proposed hybrid inverter.

Table 1. Electrical characteristics and structure dimensions of 2D TMD material.

\begin{tabular}{|c|c|c|c|c|c|}
\hline \multirow[b]{2}{*}{ Materials } & \multirow{2}{*}{$\begin{array}{l}\text { Conduction } \\
\text { Type }\end{array}$} & \multicolumn{2}{|c|}{ Mobility $\left(\mathrm{cm}^{2} / \mathrm{V} \cdot \mathrm{s}\right)$} & \multicolumn{2}{|c|}{ Band Gap (eV) } \\
\hline & & $\begin{array}{l}\text { Multilayers } \\
\text { (>10 Layers) }\end{array}$ & Monolayer & $\begin{array}{l}\text { Multilayers } \\
\text { (>10 Layers) }\end{array}$ & Monolayer \\
\hline $2 \mathrm{H}-\mathrm{MoS}_{2}$ & $n$-type & $60-200$ & $>200$ & 1.23 & 1.89 \\
\hline $2 \mathrm{H}-\mathrm{MoSe}_{2}$ & $n$-type & $160-260$ & 50 & 1.09 & 1.57 \\
\hline $2 \mathrm{H}-\mathrm{MoTe}_{2}$ & $p$-type & 40 & $\mathrm{~N} / \mathrm{A}$ & 0.93 & 1.08 \\
\hline $2 \mathrm{H}-\mathrm{WS}_{2}$ & $n$-type & 20-100 & 0.2 & 1.35 & 1.98 \\
\hline $2 \mathrm{H}-\mathrm{WSe} \mathrm{e}_{2}$ & $p$-type & $120-150$ & $30-180$ & 1.20 & 1.66 \\
\hline $1 \mathrm{~T}^{\prime}-\mathrm{WTe}_{2}$ & $\mathrm{~N} / \mathrm{A}$ & $6000-44,000$ & $20-21,000$ & \multicolumn{2}{|c|}{ Semimetal/metal } \\
\hline Materials & $\begin{array}{c}{ }^{\alpha} \text { Interlayer } \\
\text { Distance (§̊) }\end{array}$ & $\beta_{\text {vdW Gap (Å) }}$ & $\begin{array}{c}\mathrm{MX}_{2} \\
\text { Sandwich } \\
\text { Thickness (Å) }\end{array}$ & $\begin{array}{l}\text { M-X Bond } \\
\text { Length (̊) }\end{array}$ & $\begin{array}{c}\gamma \mathbf{M} \mid \mathbf{M} \\
\text { Distance }(\AA)\end{array}$ \\
\hline $2 \mathrm{H}-\mathrm{MoS}_{2}$ & 6.15 & 2.98 & 3.17 & 2.42 & 3.16 \\
\hline $2 \mathrm{H}-\mathrm{MoSe}_{2}$ & 6.47 & 3.24 & 3.23 & 2.49 & 3.29 \\
\hline $2 \mathrm{H}-\mathrm{MoTe}_{2}$ & 7.28 & 3.68 & 3.60 & 2.72 & 3.52 \\
\hline $2 \mathrm{H}-\mathrm{WS}_{2}$ & 6.16 & 3.02 & 3.14 & 2.40 & 3.15 \\
\hline $2 \mathrm{H}-\mathrm{WSe} \mathrm{e}_{2}$ & 7.00 & 3.76 & 3.24 & 2.49 & 3.29 \\
\hline $1 \mathrm{~T}^{\prime}-\mathrm{WTe}_{2}$ & 7.02 & $3.80-3.90$ & $3.50-4.00$ & $2.71-2.82$ & 2.86 \\
\hline
\end{tabular}

$\overline{{ }^{\alpha}}$ Distance the $\mathrm{M}$ atomic planes in two neighboring layers. ${ }^{\beta}$ Closest distance between the $\mathrm{X}$ atomic planes in two neighboring layers. ${ }^{\gamma}$ Closest distance between two $\mathrm{M}$ atoms (also between two $\mathrm{X}$ atoms). Data collected from the following references: [66-71]. 
a

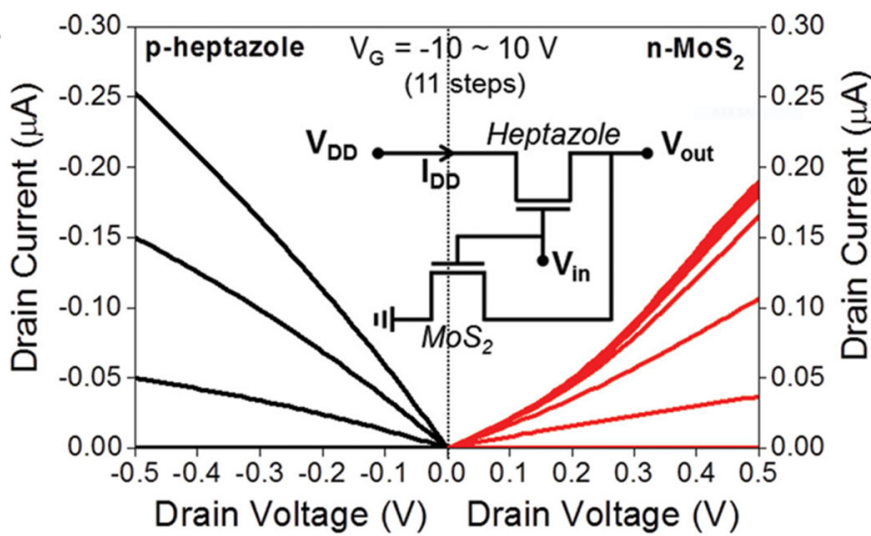

C
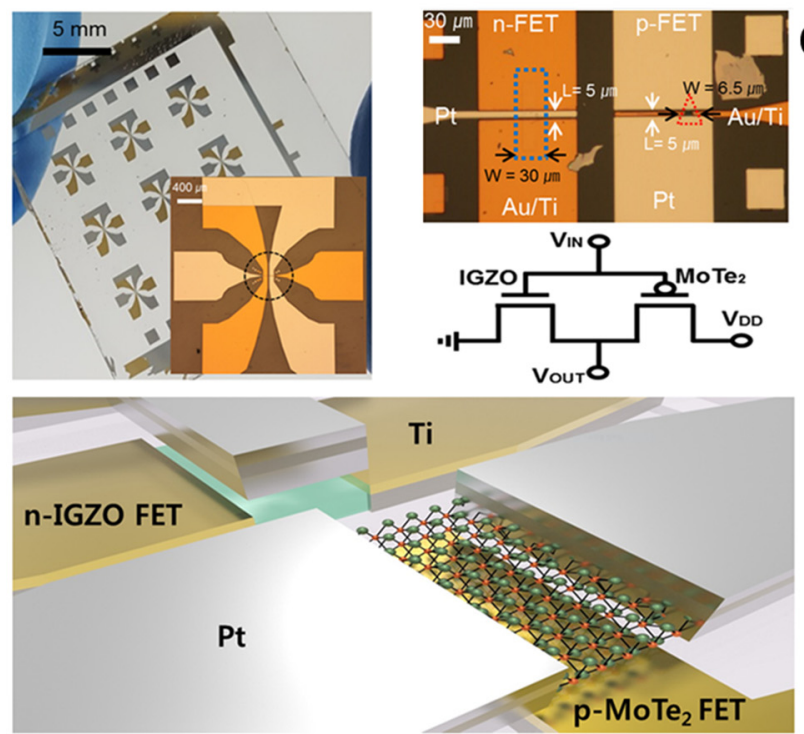

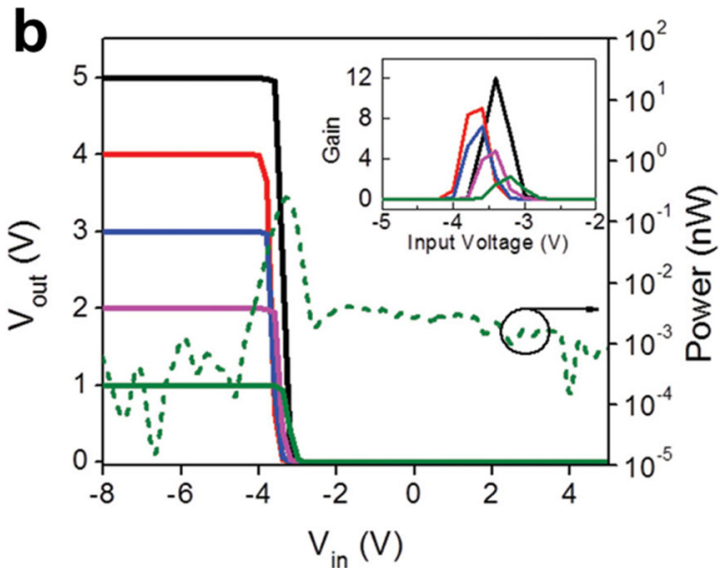

b
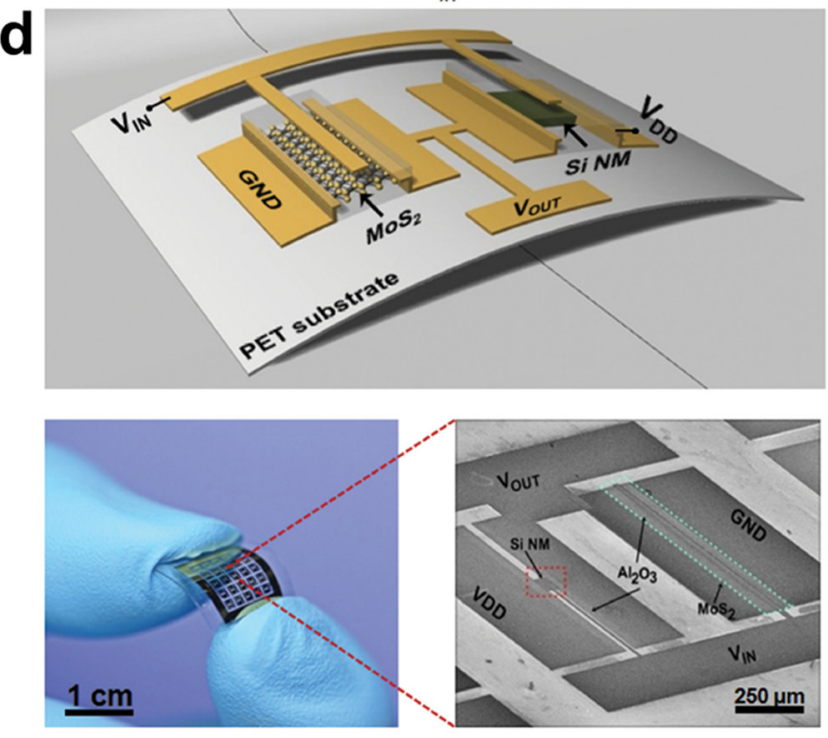

Figure 1. (a) $I_{\mathrm{D}}-V_{\mathrm{D}}$ output curve of $n-\mathrm{MoS}_{2}$ and $p$-heptazole channel FETs. (b) The voltage transfer characteristics of a hybrid CMOS inverter under supply voltages of $1 \mathrm{~V}$ to $5 \mathrm{~V}$. The dashed curve shows power consumption at $1 \mathrm{~V}$ (adapted from [63] with permission from John Wiley and Sons). (c) Patterned CMOS inverter arrays, an OM image of the hybrid inverter fabricated on glass, and a 3D schematic of the hybrid CMOS inverter (adapted from [64] with permission from the American Chemical Society). (d) A 3D illustration of an Si NM-MoS 2 -based complementary inverter built on a plastic substrate, and a photographic image of a large-area $5 \times 5$ array of a CMOS inverter patterned on PET, where the magnified panel shows the scanning electron microscope (SEM) image (adapted from [65] with permission from John Wiley and Sons).

\subsection{Metal Oxide Semiconductors}

Metal oxide semiconductors provide many opportunities in various application areas based on their great electrical properties and simple synthesis methods [72,73]. Because the large metal ns orbital of metal oxide sufficiently overlaps an adjacent metal s orbital without significant influence on the existing oxide [74], the metal oxide can maintain high electrical performance regardless of its shape and the bending of the material [75]. Additionally, metal oxide has a very mild synthesis condition, which is highly compatible with applications on a flexible substrate such as polyethylene terephthalate (PET) and polyimide (PI) $[75,76]$. However, the formation energy of the native acceptors is higher than that of the native donors such as oxygen vacancy, resulting in constraint on the hole generation. Further, the strong localization of the valence band maximum (VBM) to oxygen ions leads to a large hole effective mass and low mobility [77-79]. For this reason, most metal oxide semiconductors are an $n$-type material, and even $p$-type metal oxide semiconductors such as $\mathrm{CuO}, \mathrm{SnO}$, and $\mathrm{NiO}$ show poor charge mobility [80]. Moreover, because most of the low-temperature deposition techniques of metal oxide semiconductors have mainly considered $n$-type materials (for example, indium oxide $\left(\operatorname{In}_{2} \mathrm{O}_{3}\right)$, indium 
zinc oxide (IZO), and IGZO), efforts to implement $p$-type metal oxide devices on flexible substrates are still lacking [81,82]. In 2019, Luo et al. implemented a low-voltage, highperformance complementary inverter with an $n$-channel IZO TFT and a $p$-channel chiralityenriched $(9,8)$ semiconducting single-walled carbon nanotube (SWCNT) FET using a partial printing method [80]. Inkjet printing is a highly fascinating process for fabricating TFTs or integrating CMOS circuits because of customizability based on patterned deposition and a simple patterning process for a large-scale array. The author introduced IZO, a type of metal oxide, as a candidate for ink material because of its excellent electrical characteristics and environmental stability (Figure 2a). The hybrid CMOS inverter presented a high voltage gain of $45 \mathrm{v} / \mathrm{v}$ with low-power consumption of $400 \mathrm{nW}$. Moreover, based on a well-matched $p$-TFT and $n$-TFT, all noise margins showed more than $0.73 \mathrm{~V}(\sim 73 \%$ of the $\left.1 / 2 V_{D D}\right)$. In 2015 , Honda et al. demonstrated a temperature-response, vertically integrated $\mathrm{CNT}$ and IGZO hybrid inverter, and evaluated it by integrating the temperature sensor on a third layer [83]. The IGZO and CNT TFT were deposited on the first and second polyimide layers, and each layer was stacked vertically. The proposed vertical hybrid inverter showed a good voltage gain of $45 \mathrm{v} / v$ with $6.9 \mathrm{nW} \mathrm{mm}^{-1}$ low-power consumption. Mechanical flexibility in the vertical hybrid inverter was also evaluated by bending it, depending on the curvature radius, from flat to $2.6 \mathrm{~mm}$. The peak gain and the threshold voltage of the hybrid inverter exhibited a uniform level of value, regardless of the curvature radius, and showed stable performance and durability even in the 1000-cycle bending test, as shown in Figure 2b. The $I_{D S^{-}} V_{G S}$ curves of the CNT and IGZO TFT changed in proportion to the temperature variation, implementing a temperature-response hybrid inverter. As temperature increased, the threshold voltage of the hybrid inverter decreased linearly. In 2020, Lee et al. integrated a hybrid inverter using $n$-IGZO and $p$-WSe ${ }_{2}$ applied to two circuit models [84]: (1) a complementary metal oxide semiconductor with an $n$-channel IGZO and a $p$-channel $\mathrm{WSe}_{2}$ (Figure 2c,d), and (2) a heterojunction $p$-WSe $2 / n$-IGZO diode-load inverter. Introducing a WSe $2 /$ IGZO diode instead of a WSe $\mathrm{W}_{2}$ TFT increased the voltage gain from $6.5 \mathrm{v} / \mathrm{v}$ to $14 \mathrm{~V} / \mathrm{V}$, and low power consumption of just a few nanowatts was achieved. Moreover, the photo-response characteristic of the $\mathrm{WSe}_{2} / \mathrm{IGZO}$ diode allowed variations in output voltage under illumination.

\subsection{Organic Semiconductors}

Organic semiconductors have many advantages such as flexibility, lightness, and elaborate control of material properties through molecular structure control. For this reason, organic semiconductors are being actively utilized in applications such as flexible/wearable displays and bio or chemical sensors. [85-88]. Moreover, because organic semiconductors (i.e., pentacene, fused aromatic compound, and rubrene) are representative $p$-type material, combination with the $2 \mathrm{D}$ material or oxide semiconductor can produce significant synergistic effects $[89,90]$. However, many studies are still in progress to improve their limited electrical properties, vulnerability to temperature, and instability in the surrounding environment [91]. In 2016, Jeong et al. introduced a photocurable polymer precursor, zinc diacrylate (ZDA), to fabricate a patternable organic/inorganic hybrid inverter [46]. Organic- and metal oxide-based semiconductors are highly promising candidates because of their low fabrication cost and simple patterning process. In a commercial application of a solution processed $\mathrm{ZnO}$, the author noticed two requirements for integrating a circuit: (1) a simple patterning process without photolithography, and (2) low operating voltage for device operational stability. This report presented zinc diacrylate-enabled synthesis of a patterned $\mathrm{ZnO}$ with a simple UV polymerization and annealing process. Pentacene was utilized as a $p$-type organic semiconductor in the organic/inorganic hybrid inverter. By using high dielectric film, $\mathrm{Al}_{2} \mathrm{O}_{3} / \mathrm{TiO}_{2}$, to reduce the operation voltage, both organic and inorganic TFTs exhibited great output (Figure $3 a$ ) and a transfer characteristic (Figure $3 b$ ) under low operation voltages from -5 to $3 \mathrm{~V}$. Moreover, the hybrid inverter showed a voltage gain as high as $6.5 \mathrm{v} / \mathrm{v}$ (Figure 3c). In 2020, Ye et al. introduced a highly functional inkjet printing method that can print zinc-tin oxide (ZTO) at a high-resolution nanoscale 
assisted by an applied electrostatic field [92]. By using electrohydrodynamic (EHD) inkjet printing, a ZTO TFT was fabricated as an $n$-channel semiconductor after a simple annealing process, whereas $\mathrm{C}_{18}$-DNTT was utilized as a $p$-channel semiconductor for the organic/inorganic hybrid inverter (Figure 3d). The resulting inverter demonstrated a high voltage gain of over $30 v / v$ at a drain voltage of $50 \mathrm{~V}$ (Figure 3e).

a

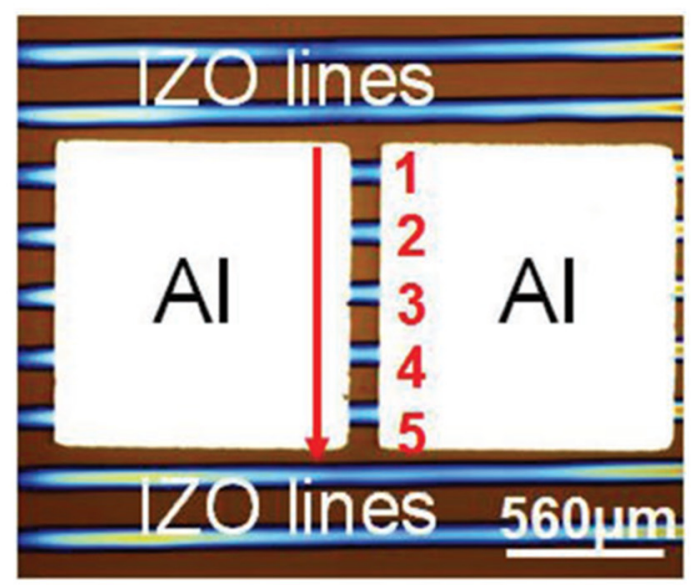

C

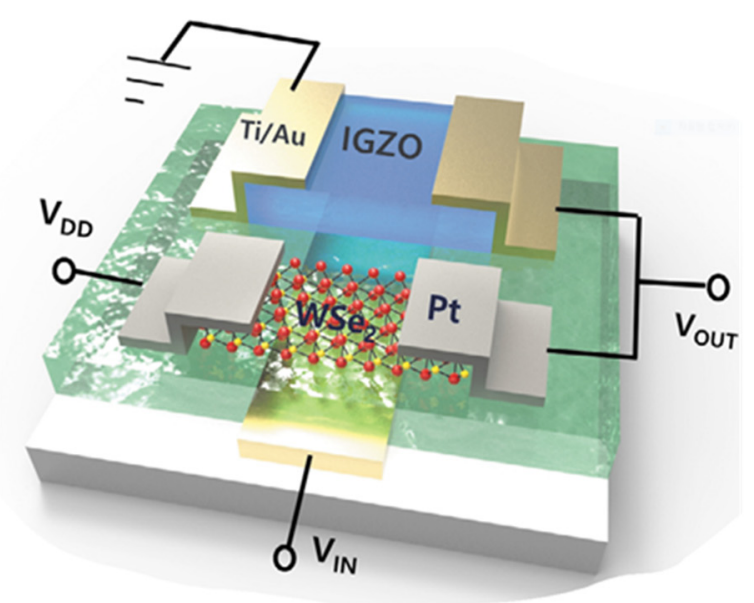

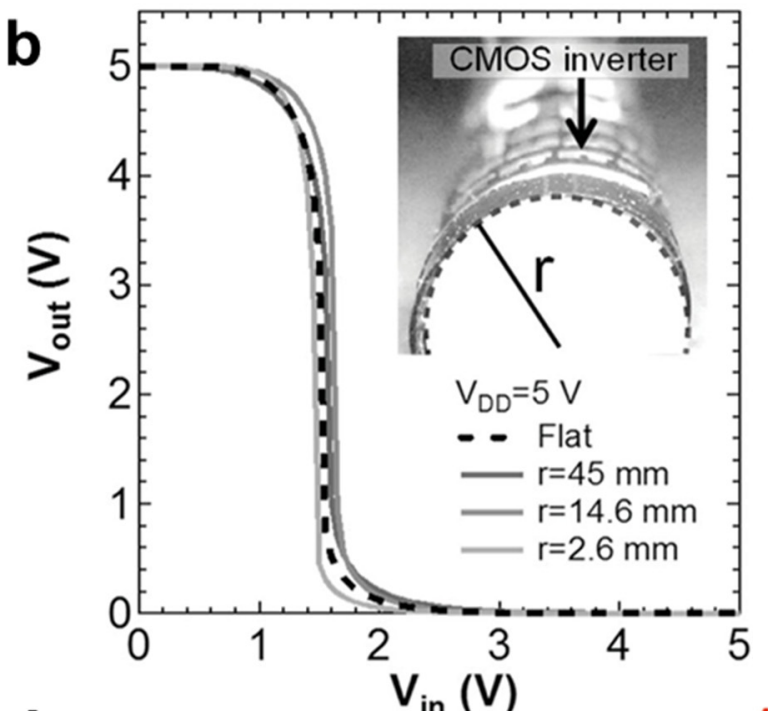
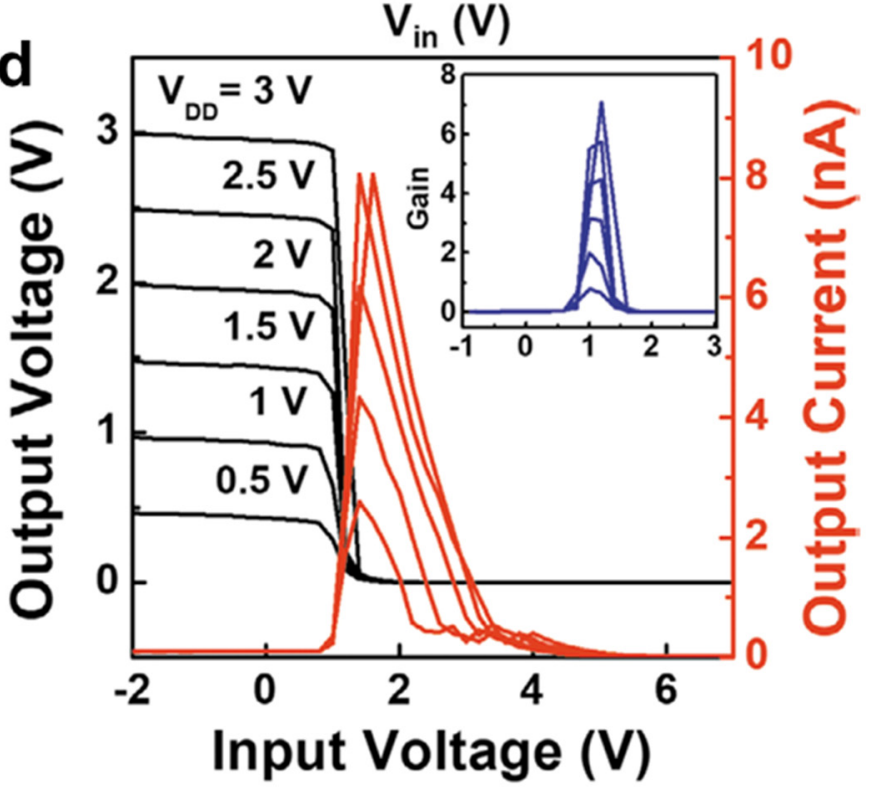

Figure 2. (a) Top view OM image of an IGZO TFT fabricated with an inkjet printing method (adapted from [80] with permission from John Wiley and Sons). (b) Output voltage characteristics of a 3D CMOS inverter allowing a bending radius up to $2.6 \mathrm{~mm}$ (adapted from [83] with permission from John Wiley and Sons). (c) A 3D illustration of a CMOS inverter consisting of $p$-WSe 2 and $n$-IGZO FETs fabricated on a glass substrate. (d) Voltage transfer characteristic curves (black) with voltage gain (inset) and output current (red) of proposed CMOS inverter as obtained from 0.5 to $3 \mathrm{~V}$ of $V_{D D}$ (adapted from [84] with permission from John Wiley and Sons). 
a

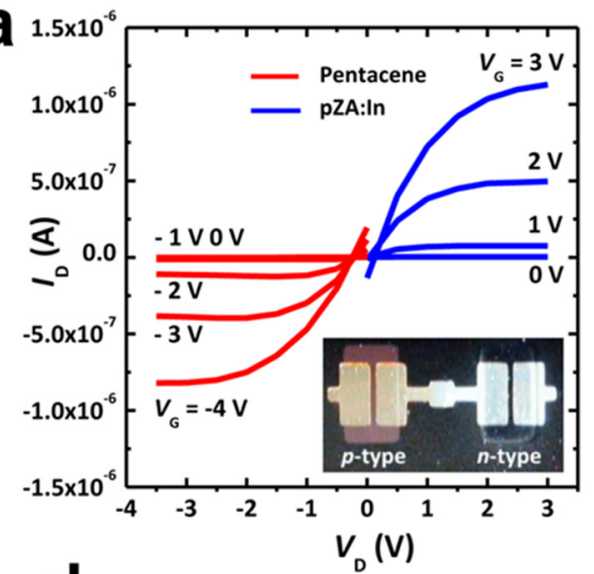

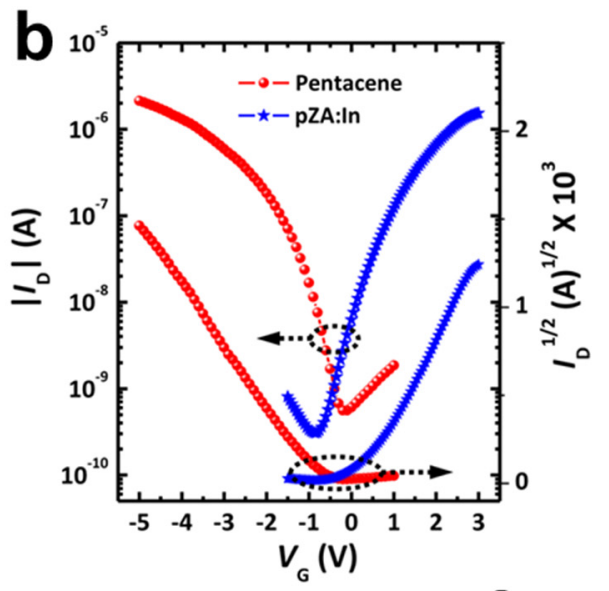
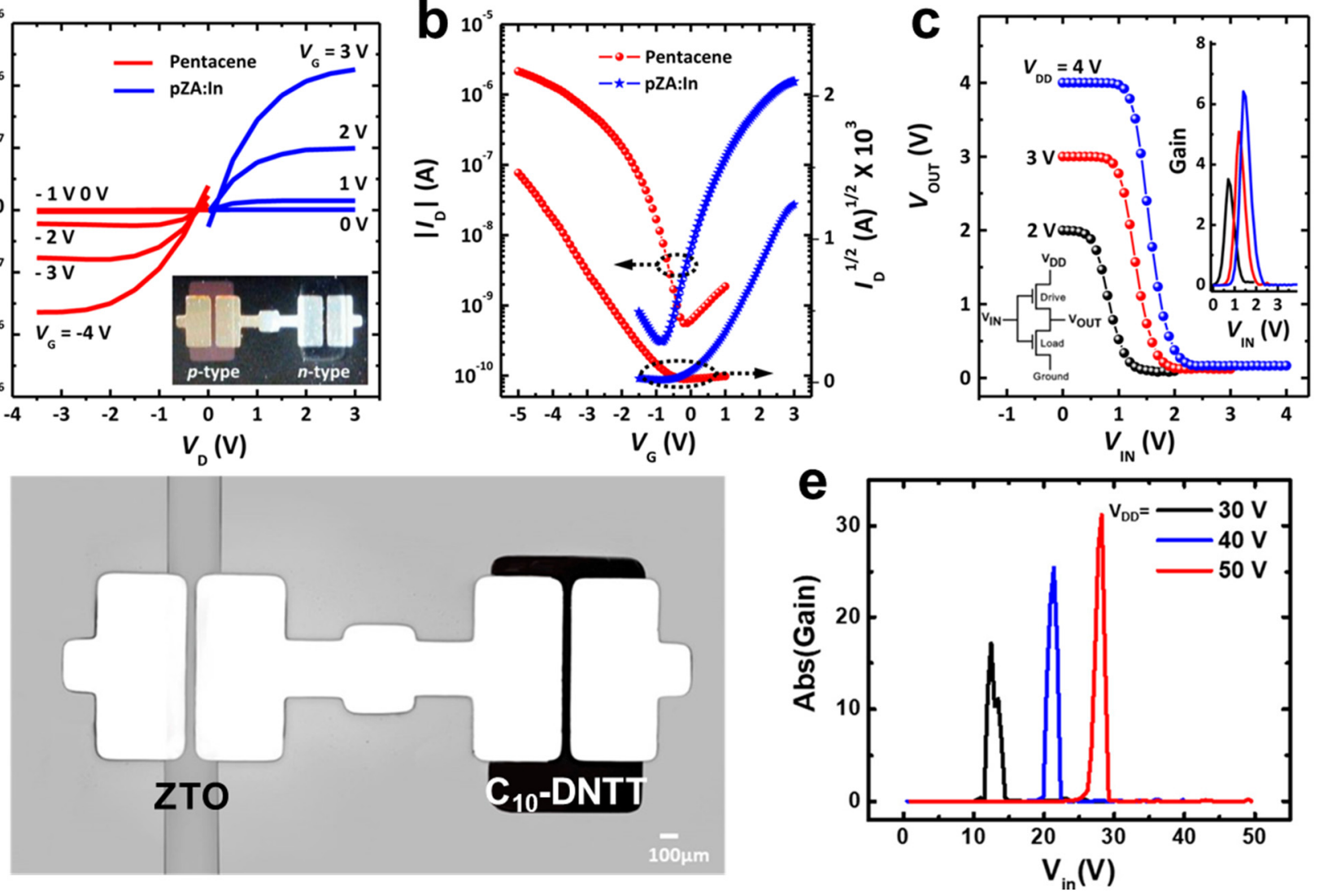

Figure 3. (a) Transfer characteristics of ZnO TFTs depending on indium doping. (b) Transfer characteristics and (c) output voltage characteristics of the pentacene and pZA:In-ZnO TFTs (adapted from [46] with permission from the American Chemical Society). (d) Top view OM image of a hybrid inverter comprising a printed ZTO transistor and a $\mathrm{C}_{10}-\mathrm{DNTT}$ transistor. (e) The voltage gains in the CMOS hybrid inverter under three $V_{D D}$ conditions $\left(V_{D D}=30,40\right.$, and $\left.50 \mathrm{~V}\right)($ adapted from [92] with permission from MDPI).

\subsection{Metal-Halide Perovskite}

Metal-halide perovskites (MHPs) have been mostly utilized in photoelectric applications like solar cells and light-emitting diodes because of their strong absorption coefficient and tunable optical bandgap [93-95]. MHP is an especially good $p$-type semiconductor, and an excellent counterpart to an $n$-type inorganic semiconductor $[96,97]$. We additionally provided electrical characteristics of representative $p$-type organic semiconductors and perovskites in Table 2. However, satisfying good quality in the semiconductor material and for mass production is still difficult, and ion migration makes MHP insensitive to gating [98]. For this reason, many attempts are still being made to fabricate MHP-based electronics. In 2019, Len et al. introduced a straddling-gap (type-I) organic semiconductor/metalhalide perovskite heterojunction to obtain state-of-the-art photogain of $15 \mathrm{v} / \mathrm{v}$ and tunable photoresponsivity [98]. Straddling-gap (type-I) indicates that the bandgap of one semiconductor (in this case MHP) is completely included in that of another semiconductor (in this case organic semiconductor). Type-I FA ${ }_{0.83} \mathrm{Cs}_{0.17} \mathrm{PbI}_{2.7} \mathrm{Br}_{0.3}$ (FACs)/ $\mathrm{C}_{8}$-BTBT heterostructure makes it easy to preserve the hole majority of the photocarriers at the valence band of the MHP. The preserved photocarriers were transported under the regime of off-state of the FAC/ $\mathrm{C}_{8}$-BTBT heterojunction phototransistors (HJPT) and changed the on/off current ratio. To compare the photoresponsivity along with band structure, the author investigated type-II FAC $/ \mathrm{C}_{16}$-BTBT HJPT, and Type-I FAC $/ \mathrm{C}_{8}$-BTBT HJPT exhibited photoresponsivity at off-state. To access performance of the proposed phototransistor, a PMOS-like photo-inverter was fabricated using two of the same FAC $/ \mathrm{C}_{8}$-BTBT HJPTs. When illuminated on a HJPT 1, as shown in Figure 4a, the voltage transfer curve showed a 
large output voltage of $-10 \mathrm{~V}$ at the lowest intensity of light. The maximum voltage gain remained at a relatively unchanged value of $15 v / v$ regardless of light intensity, but the input voltage at maximum amplification $\left(\mathrm{A}_{\mathrm{i}, \max }\right)$ was shifted from -5 to $-4 \mathrm{~V}$ as the light intensity increase from 7 to $2821 \mu \mathrm{W} \cdot \mathrm{cm}^{-2}$ (Figure $4 \mathrm{~b}$ ). In 2020, Zhu et al. synthesized a highly reliable, lead-free perovskite-based TFT and investigated the feasibility of $p$-type transistor as an inverter application (Figure 4c) [99]. The stubborn ion migration, making it insensitive to the applied bias, inhibited the use of perovskite as the active material for transistors. The author overcame poor synthesis quality with the following solutions: (1) grain boundary passivation using extra PEAI, (2) introduction of Sn powder to reduce oxidation of the Sn precursor, and (3) grain crystallization engineering through the addition of Lewis bases. As a result, the proposed (PEA) ${ }_{2} \mathrm{SnI}_{4}$ TFT achieved good electrical performance (mobility $=3.5 \mathrm{~cm}^{2} / \mathrm{V} \cdot \mathrm{s}$, on/off ratio $=3.4 \times 10^{6}$ ) in $p$-type current behavior. The perovskite-based complementary inverter was fabricated using an $n$-type IGZO TFT and $p$-type (PEA) ${ }_{2} \mathrm{SnI}_{4}$ TFT, which showed a large gain of $30 v / v$ with a high noise margin of $70 \%$ at $V_{\mathrm{DD}}$ of $14 \mathrm{~V}$, and the performance reliability was confirmed through 100 devices evaluation (Figure $4 \mathrm{~d}-\mathrm{f}$ ).

\subsection{Carbon Nanotubes}

The carbon nanotube (CNT) is a highly promising $p$-type semiconductor material because of its outstanding electrical and optical properties, which originate from a unique one-dimensional structure [104]. Moreover, the inkjet printing method can produce a patterned CNT on any kind of substrate, and much research has achieved remarkable accomplishments in fabricating CNT FETs $[105,106]$. Combination with an $n$-type material can extend the opportunity for applying the CNT $p$-type transistor to a CMOS inverter. Nevertheless, the practicality of CNTs for CMOS inverters still needs further improvement to resolve the inadequate air stability and limited tunability $[107,108]$. In 2020, Luo et al. manufactured a radiation-hard and repairable complementary hybrid inverter using a simple inkjet printing method [109]. The CNT and $\mathrm{In}_{2} \mathrm{O}_{3}$, which were regarded as favorable candidates for printable conducting materials, were used as $p$-type and $n$-type transistors for the proposed hybrid inverter (Figure 5a). Additionally, the PS-PMMA/[EMIM][TFSI] covered two transistors as the gate dielectric layer and served to passivate from the strong radiation. The hybrid inverter showed ultralow power consumption of $9.7 \mu \mathrm{W}$ at a drain voltage of $0.8 \mathrm{~V}$. Moreover, the voltage gain increased to $11.5 \mathrm{v} / \mathrm{v}$ and a large noise margin of $75 \%$ was exhibited (Figure $5 \mathrm{~b}$ ). To confirm stability under radiation, probing of the voltage transport curve was conducted, depending on an intensity of the Co-60 $\gamma$ irradiation. In 2018, Yoon et al. demonstrated an optimization process of hybrid integration of a $p$-type carbon nanotube TFT and an $n$-type IGZO TFT (Figure 5c-e) [110]. Because the CNT and IGZO are representative $p$-type and $n$-type materials, respectively, the difficulty in manufacturing a homogenous complementary inverter using only the CNT or IGZO was resolved by integrating a hybrid inverter. In this regard, the author optimized the fabrication condition of the complementary microelectronic circuits by adjusting the CNT deposition time and the oxygen flow rate during IGZO sputtering. The proposed hybrid inverter exhibited an optimized voltage gain of $108 v / v$ at the oxygen flow rate of $0.1 \mathrm{sccm}$ and CNT deposition time of $5 \mathrm{~min}$.

Table 2. The electrical properties of perovskite and organic semiconductors.

\begin{tabular}{ccccccc}
\hline Materials & $\begin{array}{c}\text { Conduction } \\
\text { Type }\end{array}$ & $\begin{array}{c}\text { On/off } \\
\text { Current Ratio }\end{array}$ & $\begin{array}{c}\text { Mobility } \\
\left(\mathbf{c m}^{2} / \mathbf{V} \cdot \mathbf{s}\right)\end{array}$ & $\begin{array}{c}\text { Subthreshold } \\
\text { Swing }\left(\mathbf{V} \cdot \mathbf{d e c}^{-\mathbf{1}}\right)\end{array}$ & $\begin{array}{c}\text { Threshold } \\
\text { Voltage (V) }\end{array}$ & Ref. \\
\hline$(\mathrm{PEA})_{2} \mathrm{SnI}_{4}$ & $p$-type & $3.4 \times 10^{6}$ & 3.51 & 0.8 & 7.3 & {$[99]$} \\
$\mathrm{MAPbI}_{3}$ & $p$-type & $2.5 \times 10^{4}$ & 23.2 & 0.14 & -0.57 & {$[100]$} \\
$\mathrm{C}_{10}-\mathrm{DNTT}$ & $p$-type & $10^{8}$ & 4.3 & 68 & -0.4 & {$[101]$} \\
DNTT & $p$-type & $10^{8}$ & 2.1 & 100 & -1.4 & {$[102]$} \\
Pentacene & $p$-type & $10^{7}$ & 0.8 & 75 & -0.6 & {$[103]$} \\
\hline
\end{tabular}



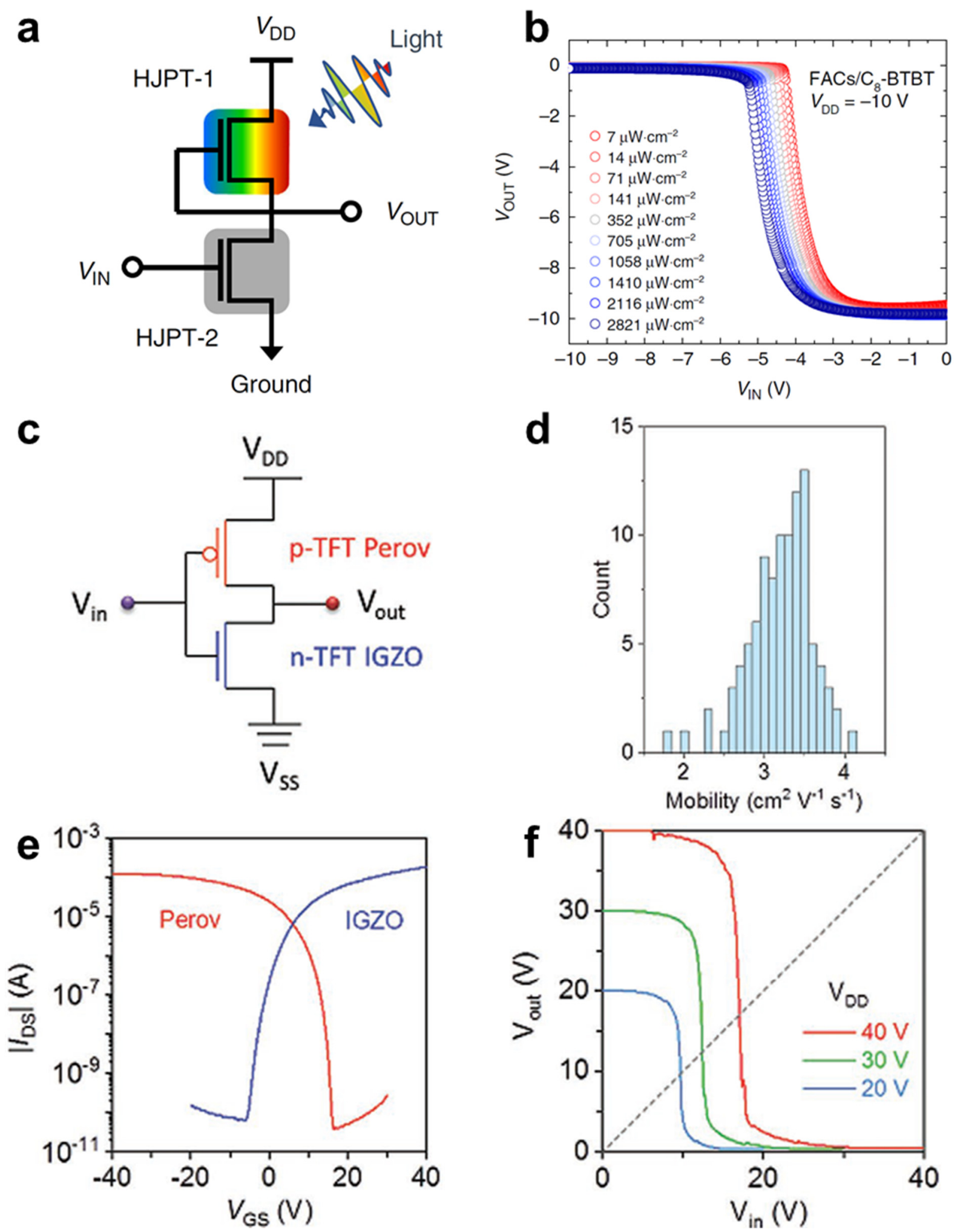

Figure 4. (a) Transfer characteristics for heterojunction phototransistor (HJPT) photo-inverters. (b) Transfer characteristics measured using a $475 \mathrm{~nm}$ LED light source under different incident light intensities for photo-inverters composed of HJPTs using FACs/C8-BTBT (adapted from [98] with permission from Springer Nature). (c) Circuit diagram of a (PEA) ${ }_{2} \mathrm{SnI}_{4} \mathrm{TFT}$ array on a four-inch $\mathrm{Si} / \mathrm{SiO}_{2}(100 \mathrm{~nm})$ wafer substrate. (d) Statistical distribution of mobility obtained from 100 TFTs across the array. (e) Transfer characteristics of perovskite and IGZO TFTs. (f) VTC of a complementary inverter at different $V_{D D}$ values (adapted from [99] with permission from John Wiley and Sons). 

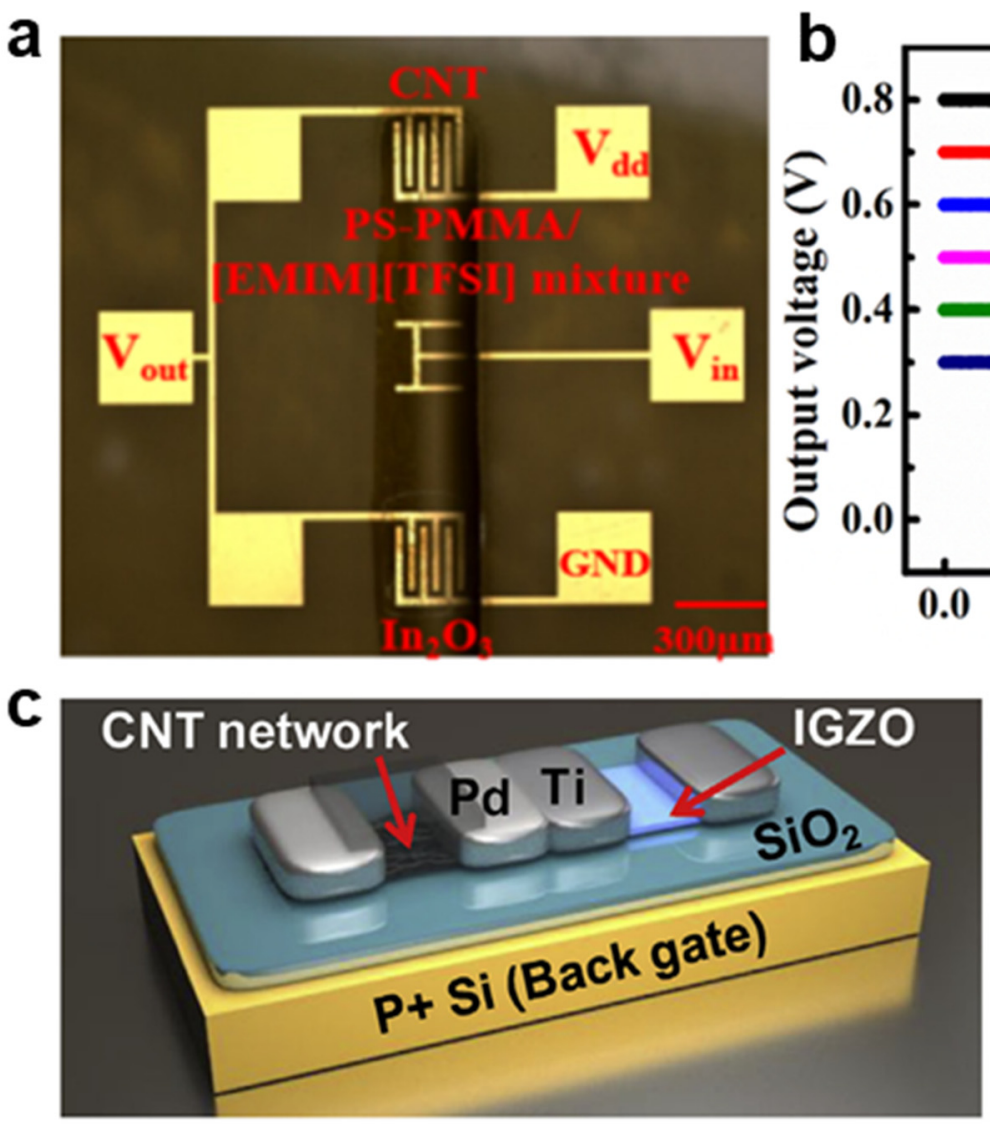

e

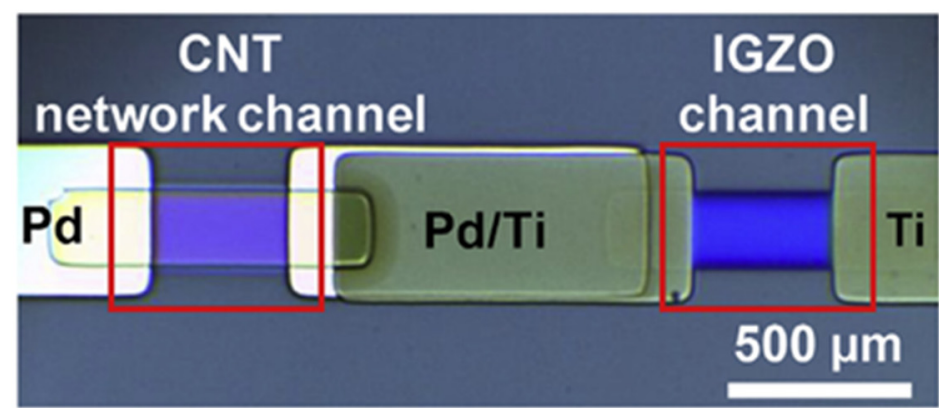

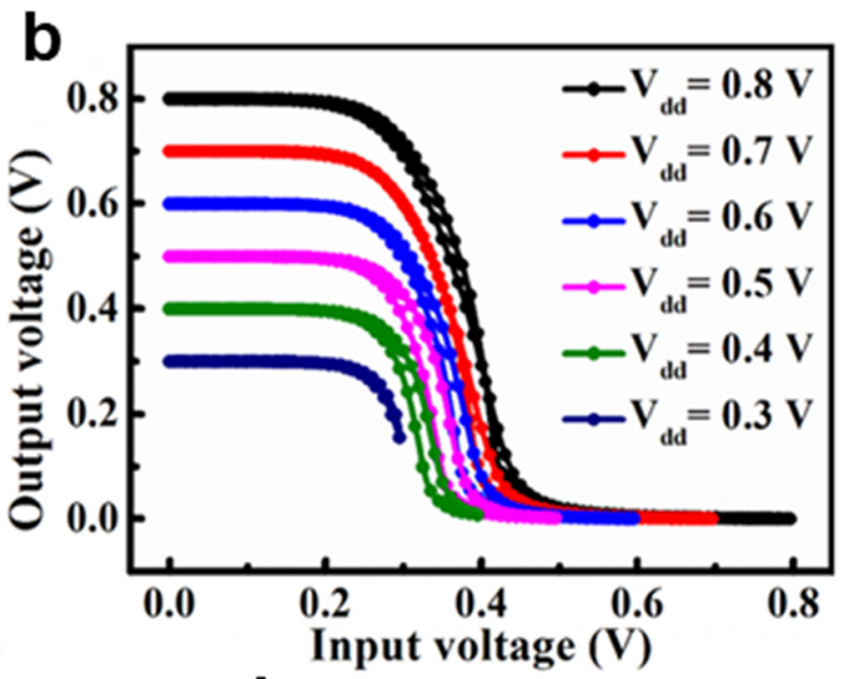

d
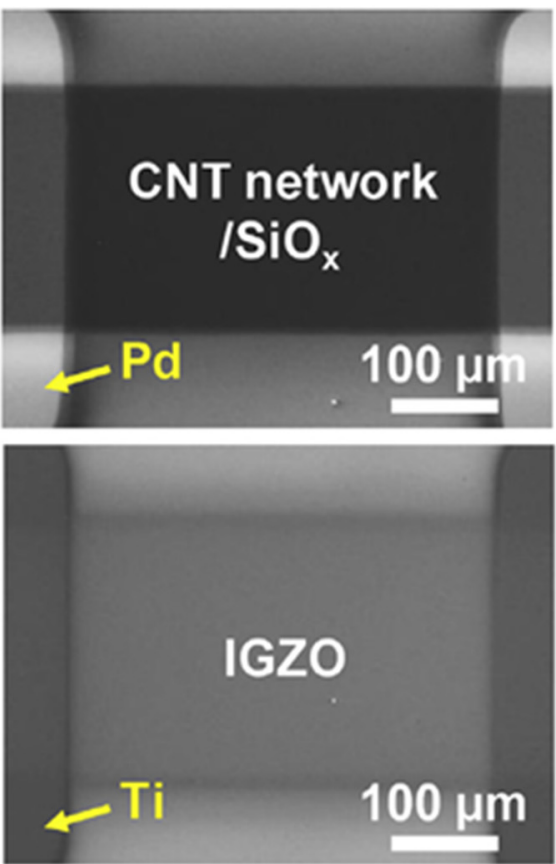

Figure 5. (a) Structure of the printed $p$-CNT and $n$ - $\mathrm{In}_{2} \mathrm{O}_{3}$ channel hybrid CMOS inverters. (b) Voltage transfer characteristics of the proposed printed hybrid CMOS inverter (adapted from [109] with permission from the American Chemical Society). (c) Structure schematic of the hybrid complementary inverter composed with $p$-type CNT and $n$-type IGZO TFTs. (d) SEM images of the CNT network channel and IGZO channel. (e) Optical microscope (OM) image of the hybrid complementary inverter (adapted from [110] with permission from Elsevier B.V.).

\section{Applications}

\subsection{Multivalued Logics}

By employing various semiconductors that possess different types of major carriers with each other, the CMOS has overcome many limitations in terms of fabrication processes and device performance enhancement. Furthermore, in some trials, an $n$ - $p$ heterojunction transistor was utilized instead of one of the transistors in the CMOS, which showed a reversed ambipolar $I-V$ curve $[26,111]$. The integrated inverter produces the third state of " $1 / 2$ " excluding " 1 " and " 0 " at the voltage transport curve, which is called a ternary inverter. Study of the ternary inverter is highly meaningful because of the high density of the data and simplification of the circuit system [112], and there were attempts to implement a hybrid ternary inverter. In 2020, Park et al. reported a photo-triggered ternary 
inverter using a rubrene nanosheet (NS) TFT and a rubrene/ $\mathrm{MoS}_{2} n-p$ heterojunction antiambipolar transistor (AAT) (Figure 6a,b) [113]. A largely unmatched threshold voltage of the $\mathrm{MoS}_{2}$ and rubrene NS created a wide on-state voltage range in the middle of the voltage sweeping range, which formed an anti-ambipolar shape in the $I-V$ curve (Figure $6 c, d$ ). Interestingly, the proposed AAT/rubrene NS hybrid inverter selectively showed ternary inverter behavior under a specific wavelength of light. Under illumination at $455 \mathrm{~nm}$ and $530 \mathrm{~nm}$ wavelengths, the threshold voltages of the $\mathrm{MoS}_{2}$ (and especially the rubrene NS) shifted, which extended the voltage range of the on-state in the AAT. The voltage range variation in the AAT induced the third state, " $1 / 2$ ", in the photo-responsive ternary inverter. In 2020, Kim et al. fabricated a fully printable ternary inverter by employing a $p$-type CNT TFT and an indium oxide/CNT $n-p$ heterojunction-based AAT (Figure 6e) [114]. Since the dimensions of the semiconductor significantly influence performance of the transistor, the number of printings in the inkjet printing method is a crucial parameter for deciding device performance. Therefore, the author modified the on-state range of the AAT by controlling the number of printings, and clearly optimized the ternary inverter behavior at four printings. As shown in the voltage transfer curve (Figure $6 \mathrm{f}$ ), the output voltage value at the " $1 / 2$ " state nearby $V_{\text {in }}=0.5 \mathrm{~V}$ was gradually changed through an increase in the number of printings. Further, by applying a three-valued input signals at $V_{\text {in }}=0,1$, and $2 \mathrm{~V}$, the dynamic operation of the proposed ternary inverter was investigated, and the result demonstrated clear output signals at $0.21,0.05$, and $0 \mathrm{~V}$, respectively. It is noted that the further advanced ternary circuit such as two-stage cascaded circuit was implemented [115].

\subsection{Vertically Stacked Complementary Inverter}

To enhance the density of data in a single pixel, not only to increase number of logic values, many studies also have tried to improve by structural modulation by stacking the complementary inverter vertically [116,117]. Their three-dimensional (3D) stacked structure can minimize the physical distance and increase the drivability of the electronic circuits by resolving the interconnection lengths and parasitic resistances [118,119]. However, the fabrication process of the vertically stacked inverter is highly complicated and difficult $[120,121]$. In 2010, Nomura et al. fabricated vertically stacked $n$-type IGZO transistors and $p$-type poly-(9,9-dioctylfluorene-co-bithiophene) (F8T2) thin film transistors on a flexible PET substrate as shown in Figure 7a,b [122]. Both transistors demonstrated low off-current and huge on/off current ratio, and the positions of the threshold voltage of each transistor certified the well-matched $I_{D S^{-}} V_{G S}$ characteristic of the $p$-F8T2 TFT and $n$-IGZO TFT. The voltage transfer characteristic of the proposed vertical hybrid inverter showed gain as high as $67 \mathrm{~V} / \mathrm{V}$. The high noise margin and low noise margin were 2.1 and $6.3 \mathrm{~V}$ at $V_{D D}=10 \mathrm{~V}$ and 10.4 and $18.3 \mathrm{~V}$ at $V_{D D}=30 \mathrm{~V}$. In 2011, Park et al. implemented vertically stacked organic/oxide hybrid inverter by using $p$-channel pentacene TFT and $n$-channel GaZnSn oxide (GZTO) TFT, as shown in Figure 7c [118]. The author investigated not only performance as a function of inverter but also operation in photogating and ferroelectric memory. The proposed hybrid vertical inverter exhibited clear inverter operation with high voltage gains of 20, 25, and $52 v / v$ at supply voltage of 3,5 , and $8 \mathrm{~V}$, respectively. Moreover, the hybrid inverter operated with a response time of 5-40 ms under $5 \mathrm{~V}$ input pulse. The response time of the proposed hybrid complementary inverter was yet not comparable with the commercial product, so further efforts to improve device performance are still necessary [123]. 

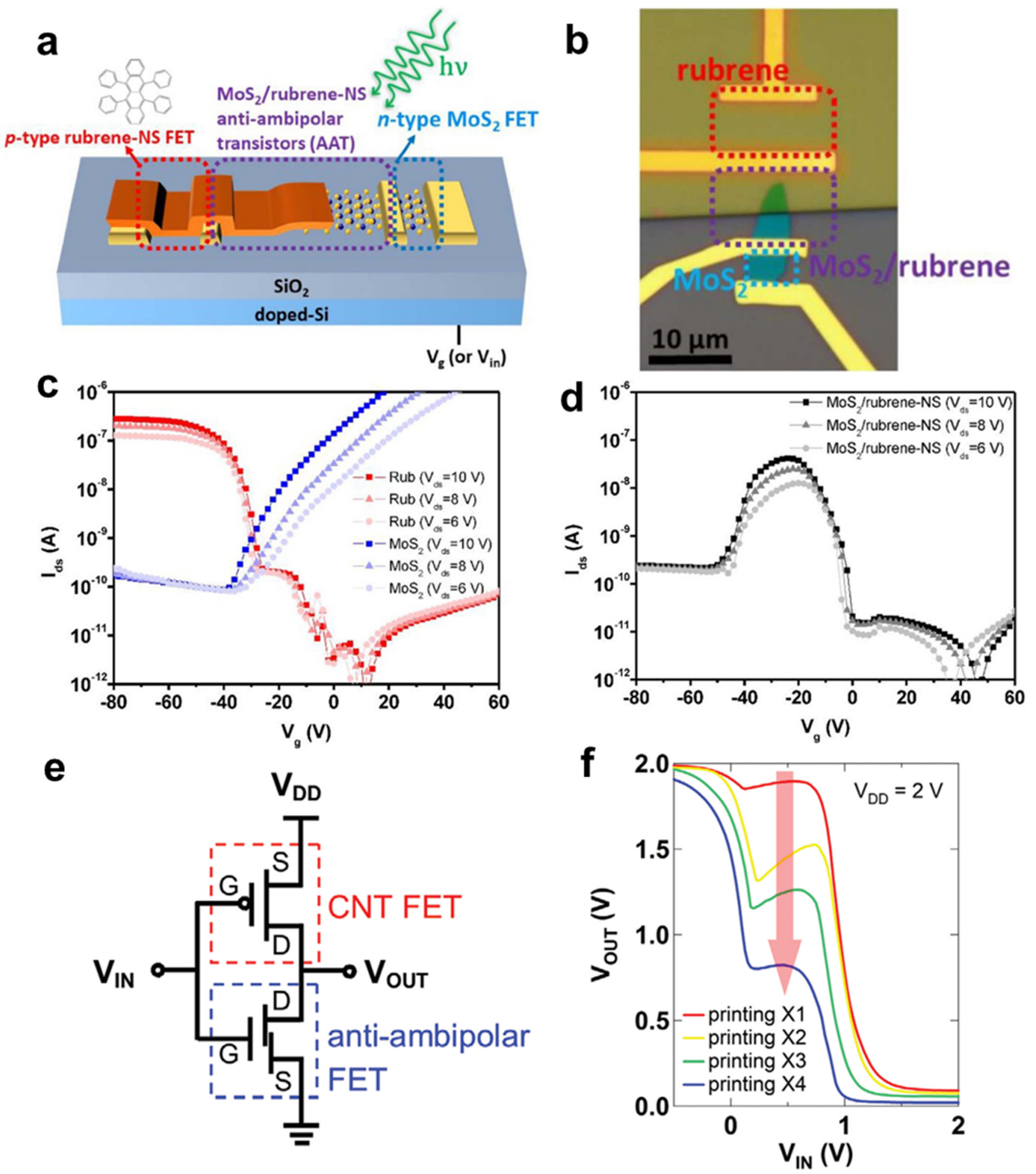

Figure 6. (a) Illustration of a ternary inverter using a lateral-type $\mathrm{MoS}_{2} /$ rubrene-NS $n$ - $p$ heterojunction FET. (b) Optical microscope image of the ternary inverter using the lateral-type $\mathrm{MoS}_{2}$ /rubrene-NS heterojunction FET. (c) Transfer characteristic curves of the rubrene-NS-based FET and the $\mathrm{MoS}_{2}$-based FET. (d) Transfer characteristic curves $\left(I_{D S}-V_{G S}\right)$ of the $\mathrm{MoS}_{2}$ / rubrene-NS $n-p$ heterojunction FET (AAT) (adapted from [113] with permission from IOP Publishing). (e) Circuit diagram of the ternary inverter composed of a CNT FET and an anti-ambipolar FET. (f) Voltage transfer characteristics of the ternary inverter (adapted from [114] with permission from John Wiley and Sons). 
a

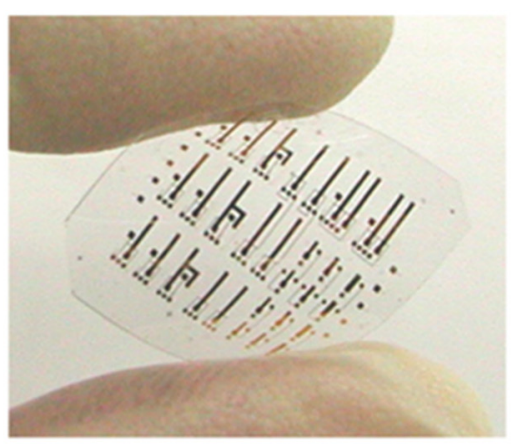

b
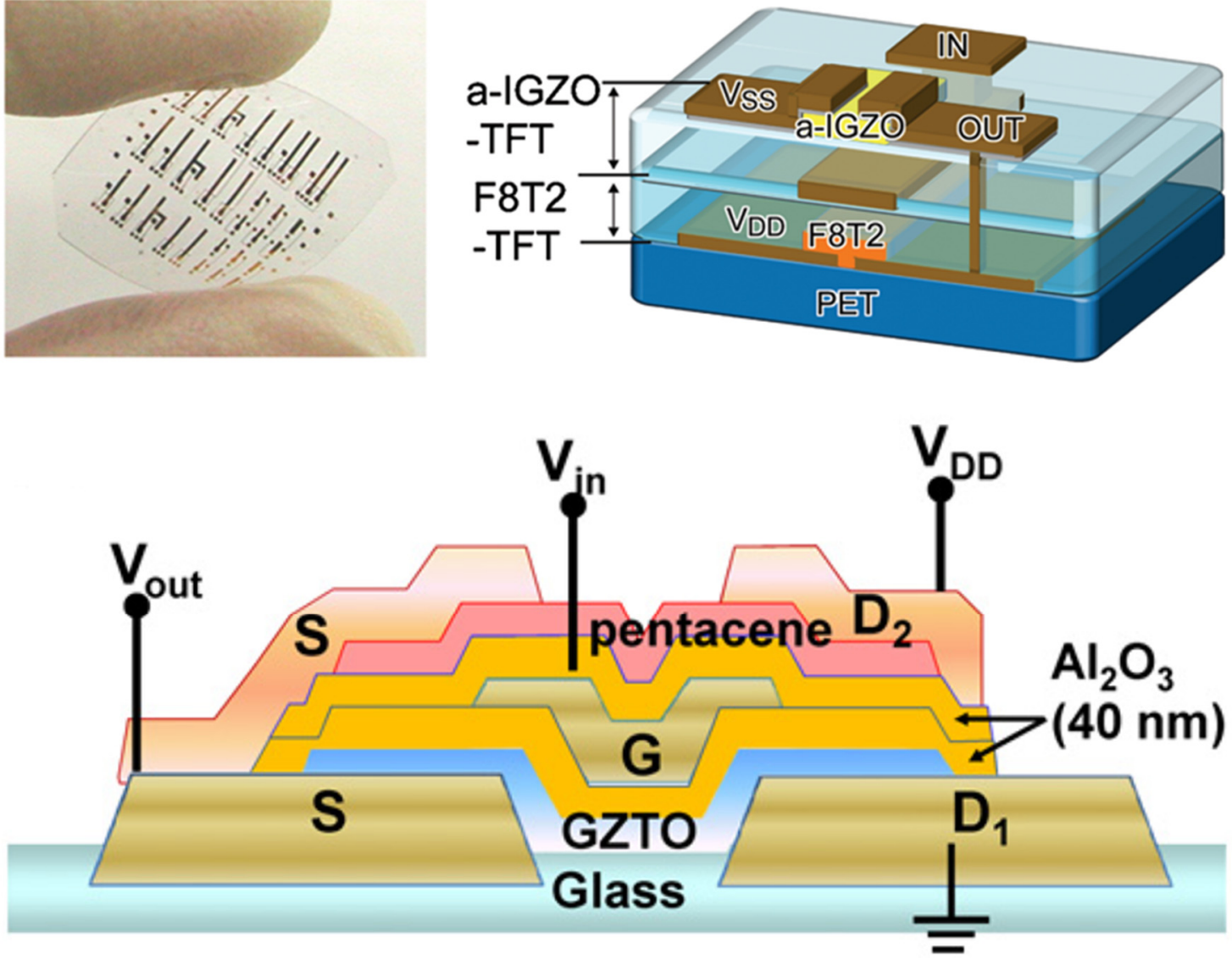

Figure 7. (a) Image of the flexible hybrid inverter comprising $n$-type IGZO TFT and $p$-type F8T2 TFT and that of (b) the device structure (adapted from [122] with permission from American Institute of Physics). (c) Illustration of a cross-section view of the Vs-CTFT inverter with $n$-type GZTO TFT and $p$-type pentacene TFT (adapted from [118] with permission from Elsevier B.V.).

\section{Conclusions and Outlook}

In this review, we present an overview of recent advances in hybrid-material combinationbased complementary circuits. Non-silicon materials are considered highly promising material because their unique material properties help to implement CMOS inverters, which obtain various functionality such as flexibility, transparency, and so on. However, their intrinsic characteristics compromise the CMOS inverter by using similar types of materials. Hybrid inverters provide solutions to many problems and allow implementation of functional inverter devices. We listed five non-silicon semiconductors and summarized the pros and cons of using them in hybrid inverters.

(1) Two-dimensional materials possess a layered structure based on van der Waals force, which assigns excellent electrical performance, high material stability in the surrounding environment, and great mechanical properties. However, their unique structure is mainly implemented with specific synthesis conditions, confining the compatibility with certain kinds of substrate.

(2) Metal oxide semiconductors are highly promising because of their mild synthesis condition, ease of fabrication for large-scale applications, and great electrical performance. However, most metal oxide semiconductors are an $n$-type material, and even $p$-type metal oxide semiconductors show poor charge mobility and a high annealing temperature.

(3) Most organic semiconductors exhibit $p$-type characteristics, unlike 2D materials and oxide semiconductors, which are very important to fabricate CMOS inverters. More- 
over, their simple synthesis process allows them to be fabricated on flexible devices. However, vulnerability to temperature and instability in the surrounding environment still remain a challenge to overcome.

(4) Strong absorption coefficients and tunable optical bandgaps of MHPs contribute to optoelectrical applications. Specifically, MHP is a good $p$-type semiconductor, which is highly compatible to fabricate hybrid inverter with an $n$-type inorganic semiconductor. Nevertheless, the practicality of perovskites for CMOS inverters still needs further improvement for good electrical quality and mass production.

(5) CNT have attracted attention for their printable synthesis method and $p$-type semiconductor characteristics. However, using CNT is still limited because of their inadequate air stability and limited tunability.

Material characteristics and preparation process of each type of semiconductor materials and their inverter performances were listed up in Tables 3 and 4 .

Table 3. Performance comparison of the hybrid complementary inverter.

\begin{tabular}{|c|c|c|c|c|c|c|c|c|}
\hline n-Type Material & $p$-Type Material & $\begin{array}{l}\text { NMOS } \\
\text { Mobility } \\
\left(\mathrm{cm}^{2} / \mathrm{V} \cdot \mathrm{s}\right)\end{array}$ & $\begin{array}{c}\text { PMOS } \\
\text { Mobility } \\
\left(\mathrm{cm}^{2} / \mathrm{V} \cdot \mathrm{s}\right)\end{array}$ & $\begin{array}{c}\text { Voltage } \\
\text { Gain }(V / V)\end{array}$ & $\begin{array}{l}\text { Noise } \\
\text { Margin }\end{array}$ & $\begin{array}{c}\text { Operation } \\
\text { Voltage (V) }\end{array}$ & $\begin{array}{l}\text { Power Con- } \\
\text { sumption } \\
(\mathrm{nW})\end{array}$ & Ref. \\
\hline $\mathrm{MoS}_{2}$ & Heptazole & 6 & 0.14 & 12 & $\mathrm{~N} / \mathrm{A}$ & 5 & 1 & [69] \\
\hline IGZO & $\mathrm{MoTe}_{2}$ & 4.2 & 22.4 & 40 & $\mathrm{~N} / \mathrm{A}$ & 5 & 300 & [70] \\
\hline $\mathrm{MoS}_{2}$ & Si NM & $\mathrm{N} / \mathrm{A}$ & $\mathrm{N} / \mathrm{A}$ & 16 & ${ }^{\alpha} \mathrm{NM}_{\mathrm{T}} 80 \%$ & 5 & 300 & [71] \\
\hline $\mathrm{IZO}$ & SWCNT & 3.01 & $3-5$ & 45 & $\begin{array}{l}\beta \mathrm{NM}_{\mathrm{H}} 77 \% \\
\gamma \mathrm{NM}_{\mathrm{L}} 83 \%\end{array}$ & 2 & 400 & [80] \\
\hline IGZO & CNT & 4.93 & 2.19 & 45 & N/A & 5 & 0.69 & [83] \\
\hline IGZO & $\mathrm{WSe}_{2}$ & $\mathrm{~N} / \mathrm{A}$ & $\mathrm{N} / \mathrm{A}$ & 6.5 & $\mathrm{~N} / \mathrm{A}$ & 3 & $\mathrm{~N} / \mathrm{A}$ & [84] \\
\hline pWA:In-ZnO & Pentacene & 0.853 & 0.718 & 6.5 & $\mathrm{~N} / \mathrm{A}$ & 4 & $\mathrm{~N} / \mathrm{A}$ & [46] \\
\hline ZTO & $\mathrm{C}_{10-\mathrm{DNTT}}$ & 1.35 & $\mathrm{~N} / \mathrm{A}$ & 31.2 & $\mathrm{~N} / \mathrm{A}$ & 50 & $\mathrm{~N} / \mathrm{A}$ & [92] \\
\hline FACs $/ \mathrm{C}_{8}$-BTBT & $\mathrm{FACs} / \mathrm{C}_{8}-\mathrm{BTBT}$ & 0.52 & 0.52 & 15 & $\mathrm{~N} / \mathrm{A}$ & -10 & $\mathrm{~N} / \mathrm{A}$ & [98] \\
\hline IGZO & $(\mathrm{PEA})_{2} \mathrm{SnI}_{4}$ & $\mathrm{~N} / \mathrm{A}$ & 3.16 & 30 & $\mathrm{NM}_{\mathrm{T}} 70 \%$ & 40 & $\mathrm{~N} / \mathrm{A}$ & [99] \\
\hline $\mathrm{In}_{2} \mathrm{O}_{3}$ & $\mathrm{CNT}$ & 2.8 & 8.6 & 11.5 & $\begin{array}{l}\mathrm{NM}_{\mathrm{H}} 82 \% \\
\mathrm{NM}_{\mathrm{L}} 75 \%\end{array}$ & 0.8 & 9700 & [109] \\
\hline IGZO & $\mathrm{CNT}$ & 12.9 & 11.7 & 108.3 & $\mathrm{~N} / \mathrm{A}$ & 20 & $\mathrm{~N} / \mathrm{A}$ & [110] \\
\hline GZTO & Pentacene & 1.2 & 0.4 & 52 & $\mathrm{~N} / \mathrm{A}$ & 8 & $\mathrm{~N} / \mathrm{A}$ & [118] \\
\hline IGZO & F8T2 & 3.2 & $1.7 \times 10^{-3}$ & 67 & $\begin{array}{l}\mathrm{NM}_{\mathrm{H}} 10.4 \mathrm{~V} \\
\mathrm{NM}_{\mathrm{L}} 18.3 \mathrm{~V}\end{array}$ & 30 & $\mathrm{~N} / \mathrm{A}$ & [122] \\
\hline
\end{tabular}

${ }^{\alpha}$ Total noise margin. ${ }^{\beta}$ High noise margin. ${ }^{\gamma}$ Low noise margin.

Table 4. Materials properties and preparation process of various semiconductor materials.

\begin{tabular}{|c|c|c|c|c|c|c|c|}
\hline Materials & Family & $\begin{array}{l}\text { Mobility } \\
\left(\mathrm{cm}^{2} / \mathrm{V} \cdot \mathrm{s}\right)\end{array}$ & $\begin{array}{l}\text { Conduction } \\
\text { Type }\end{array}$ & Preparation Method & $\begin{array}{c}\text { Band Gap } \\
(\mathrm{eV})\end{array}$ & $\begin{array}{c}\text { Material } \\
\text { Thickness (nm) }\end{array}$ & Ref. \\
\hline pentacene & Organic semiconductor & 0.718 & $p$-type & $\begin{array}{l}\text { Organic molecular } \\
\text { beam deposition }\end{array}$ & $\mathrm{N} / \mathrm{A}$ & 50 & {$[46]$} \\
\hline $\mathrm{MoS}_{2}$ & TMD & 6 & n-type & Exfoilation & 1.8 & 2 & [69] \\
\hline $\mathrm{MoTe}_{2}$ & TMD & 22.4 & $p$-type & Exfoilation & 0.94 & 4 & [70] \\
\hline IGZO & Metal oxide & 4.2 & $n$-type & $\begin{array}{l}\text { DC magnetron } \\
\text { sputtering }\end{array}$ & 2.7 & 50 & {$[70]$} \\
\hline $\mathrm{IZO}$ & Metal oxide & 3.01 & $n$-type & Inkjet printing & $>3.0$ & 23 & {$[80]$} \\
\hline SWCNT & Carbon nanotube & $3-5$ & $p$-type & Inkjet printing & 0.67 & 1.17 & [80] \\
\hline$(\mathrm{PEA})_{2} \mathrm{SnI}_{4}$ & Perovskite & 3.16 & p-type & Spin coating & $\mathrm{N} / \mathrm{A}$ & $\mathrm{N} / \mathrm{A}$ & [99] \\
\hline F8T2 & Organic semiconductor & 0.0017 & p-type & Inkjet printing & $\mathrm{N} / \mathrm{A}$ & 50 & [122] \\
\hline
\end{tabular}

Complementary inverters possess significant potential for application to not only logic components but also various sensors (such as chemical sensors [124,125], optical sensors [126], gas sensors [127], and temperature sensors [83]) and biomedical applications (such as bioelectronics [128,129] and bio-signal amplifiers $[119,130]$ ). However, challenges for integrating hybrid materials still exist; the fabrication process of $p$-type and $n$-type materials and their devices requires the separate deposition, patterning, and optimization of two heterogenous materials, increasing the complexity of the fabrication process with the ad hoc process conditions. Therefore, it is important to deeply understand the material 
intrinsic properties and discover the desirable integration process of the hybrid materials combination, and this paper is expected to provide useful guidelines for dealing with hybrid complementary integrations.

Author Contributions: G.W. performed the literature research and analysis and wrote the paper. H.Y. and T.K. initiated and supervised the work and wrote the paper. All authors have read and agreed to the published version of the manuscript.

Funding: This work was supported by the National Research Foundation of Korea (NRF) grant funded by the Korea government (MEST) (NRF2017R1A2B3011222, NRF-2020R1A2C1101647).

Data Availability Statement: Not applicable.

Conflicts of Interest: The authors declare no conflict of interest.

\section{References}

1. Nomura, K. Recent progress of oxide-TFT-based inverter technology. J. Inf. Disp. 2021, 23, 211-229. [CrossRef]

2. Meindl, J.D.; Chen, Q.; Davis, J.A. Limits on silicon nanoelectronics for terascale integration. Science 2001, $293,2044-2049$. [CrossRef]

3. Nomura, K.; Ohta, H.; Ueda, K.; Kamiya, T.; Hirano, M.; Hosono, H. Thin-film transistor fabricated in single-crystalline transparent oxide semiconductor. Science 2003, 300, 1269-1272. [CrossRef]

4. Fuchigami, H.; Tsumura, A.; Koezuka, H. Polythienylenevinylene thin-film-transistor with high carrier mobility. Appl. Phys. Lett. 1993, 63, 1372-1374. [CrossRef]

5. Klauk, H.; Gundlach, D.J.; Jackson, T.N. Fast organic thin-film transistor circuits. IEEE Electron Device Lett. 1999, $20,289-291$. [CrossRef]

6. Zhu, W.N.; Park, S.; Yogeesh, M.N.; McNicholas, K.M.; Bank, S.R.; Akinwande, D. Black phosphorus flexible thin film transistors at gighertz frequencies. Nano Lett. 2016, 16, 2301-2306. [CrossRef]

7. Chen, X.; Zhang, G.Z.; Wan, J.X.; Guo, T.; Li, L.; Yang, Y.P.; Wu, H.; Liu, C. Transparent and flexible thin-film transistors with high performance prepared at ultralow temperatures by atomic layer deposition. Adv. Electron. Mater. 2019, 5, 1800583. [CrossRef]

8. Yu, M.; Wan, H.C.; Cai, L.; Miao, J.S.; Zhang, S.M.; Wang, C. Fully printed flexible dual-gate carbon nanotube thin-film transistors with tunable ambipolar characteristics for complementary logic circuits. ACS Nano 2018, 12, 11572-11578. [CrossRef]

9. Kraft, U.; Zaki, T.; Letzkus, F.; Burghartz, J.N.; Weber, E.; Murmann, B.; Klauk, H. Low-voltage, high-frequency organic transistors and unipolar and complementary ring oscillators on paper. Adv. Electron. Mater. 2019, 5, 1800453. [CrossRef]

10. Kim, K.-T.; Kang, S.-H.; Nam, S.-J.; Park, C.-Y.; Jo, J.-W.; Heo, J.-S.; Park, S.-K. Skin-compatible amorphous oxide thin-filmtransistors with a stress-released elastic architecture. Appl. Sci. 2021, 11, 5501. [CrossRef]

11. Hong, S.Y.; Lee, Y.H.; Park, H.; Jin, S.W.; Jeong, Y.R.; Yun, J.; You, I.; Zi, G.; Ha, J.S. Stretchable active matrix temperature sensor array of polyaniline nanofibers for electronic skin. Adv. Mater. 2016, 28, 930-935. [CrossRef] [PubMed]

12. Heo, J.S.; Lee, K.W.; Lee, J.H.; Shin, S.B.; Jo, J.W.; Kim, Y.H.; Kim, M.G.; Park, S.K. Highly-sensitive textile pressure sensors enabled by suspended-type all carbon nanotube fiber transistor architecture. Micromachines 2020, 11, 1103. [CrossRef]

13. Choi, S.; Jo, W.; Jeon, Y.; Kwon, S.; Kwon, J.H.; Son, Y.H.; Kim, J.; Park, J.H.; Kim, H.; Lee, H.S.; et al. Multi-directionally wrinkle-able textile OLEDs for clothing-type displays. npj Flex. Electron. 2020, 4, 33. [CrossRef]

14. Yang, A.N.; Li, Y.Z.; Yang, C.X.; Fu, Y.; Wang, N.X.; Li, L.; Yan, F. Fabric organic electrochemical transistors for biosensors. Adv. Mater. 2018, 30, 1800051. [CrossRef]

15. Choi, M.; Park, Y.J.; Sharma, B.K.; Bae, S.-R.; Kim, S.Y.; Ahn, J.-H. Flexible active-matrix organic light-emitting diode display enabled by $\mathrm{MoS}_{2}$ thin-film transistor. Sci. Adv. 2018, 4, eaas8721. [CrossRef]

16. Park, J.; Heo, S.; Park, K.; Song, M.H.; Kim, J.-Y.; Kyung, G.; Ruoff, R.S.; Park, J.-U.; Bien, F. Research on flexible display at Ulsan National Institute of Science and Technology. npj Flex. Electron. 2017, 1, 9. [CrossRef]

17. Han, S.Y.; Jeon, K.S.; Cho, B.; Seo, M.S.; Song, J.; Kong, H. Characteristics of a-SiGe:H thin film transistor infrared photosensor for touch sensing displays. IEEE J. Quantum Electron. 2012, 48, 952-959. [CrossRef]

18. Yun, M.G.; Kim, Y.K.; Ahn, C.H.; Cho, S.W.; Kang, W.J.; Cho, H.K.; Kim, Y.-H. Low voltage-driven oxide phototransistors with fast recovery, high signal-to-noise ratio, and high responsivity fabricated via a simple defect-generating process. Sci. Rep. 2016, 6, 31991. [CrossRef]

19. Zhuang, X.; Huang, W.; Han, S.; Jiang, Y.; Zheng, H.; Yu, J. Interfacial modifying layer-driven high-performance organic thin-film transistors and their nitrogen dioxide gas sensors. Org. Electron. 2017, 49, 334-339. [CrossRef]

20. Wang, B.; Thukral, A.; Xie, Z.; Liu, L.; Zhang, X.; Huang, W.; Yu, X.; Yu, C.; Marks, T.J.; Facchetti, A. Flexible and stretchable metal oxide nanofiber networks for multimodal and monolithically integrated wearable electronics. Nat. Commun. 2020, $11,2405$. [CrossRef]

21. Yang, T.-H.; Chen, T.-Y.; Wu, N.-T.; Chen, Y.-T.; Huang, J.-J. IGZO-TFT biosensors for Epstein-Barr virus protein detection. IEEE Trans. Electron. Devices 2017, 64, 1294-1299. [CrossRef] 
22. Yang, P.; Cai, G.; Wang, X.; Pei, Y. Electrolyte-gated indium oxide thin film transistor based biosensor with low operation voltage. IEEE Trans. Electron. Devices 2019, 66, 3554-3559. [CrossRef]

23. Yamamoto, Y.; Harada, S.; Yamamoto, D.; Honda, W.; Arie, T.; Akita, S.; Takei, K. Printed multifunctional flexible device with an integrated motion sensor for health care monitoring. Sci. Adv. 2016, 2, e1601473. [CrossRef]

24. Rao, Z.; Ershad, F.; Almasri, A.; Gonzalez, L.; Wu, X.; Yu, C. Soft electronics for the skin: From health monitors to human-machine interfaces. Adv. Mater. Technol. 2020, 5, 2000233. [CrossRef]

25. Yoo, H.; On, S.; Lee, S.B.; Cho, K.W.; Kim, J.J. Negative transconductance heterojunction organic transistors and their application to full-swing ternary circuits. Adv. Mater. 2019, 31, 1808265. [CrossRef]

26. On, S.; Kim, Y.-J.; Lee, H.-K.; Yoo, H. Ambipolar and anti-ambipolar thin-film transistors from edge-on small-molecule heterostructures. Appl. Surf. Sci. 2021, 542, 148616. [CrossRef]

27. Kim, S.; Hong, S.; Yoo, H. Location-dependent multi-parameter detection behaviors using hetero-interfaced organic anti-ambipolar phototransistors. Sen. Actuator A Phys. 2021, 330, 112888. [CrossRef]

28. Yang, Y.; Yang, J.Y.; Yin, W.L.; Huang, F.M.; Cui, A.Y.; Zhang, D.X.; Li, W.W.; Hu, Z.G.; Chu, J.H. Annealing time modulated the film microstructures and electrical properties of P-type CuO field effect transistors. Appl. Surf. Sci. 2019, 481, 632-636. [CrossRef]

29. Lee, S.; Lee, W.; Jang, B.; Kim, T.; Bae, J.; Cho, K.; Kim, S.; Jang, J. Sol-gel processed p-type CuO phototransistor for a near-infrared sensor. IEEE Electron Device Lett. 2018, 39, 47-50. [CrossRef]

30. Bae, J.H.; Lee, J.H.; Park, S.P.; Jung, T.S.; Kim, H.J.; Kim, D.; Lee, S.W.; Park, K.S.; Yoon, S.; Kang, I.; et al. Gallium doping effects for improving switching performance of p-type copper(I) oxide thin-film transistors. ACS Appl. Mater. Inter. 2020, 12, 38350-38356. [CrossRef]

31. Cardenas, J.A.; Catenacci, M.J.; Andrews, J.B.; Williams, N.X.; Wiley, B.J.; Franklin, A.D. In-place printing of carbon nanotube transistors at low temperature. ACS Appl. Nano Mater. 2018, 1, 1863-1869. [CrossRef]

32. Liang, Y.Q.; Xiao, M.M.; Wu, D.; Lin, Y.X.; Liu, L.J.; He, J.P.; Zhang, G.J.; Peng, L.M.; Zhang, Z.Y. Wafer-scale uniform carbon nanotube transistors for ultrasensitive and label-free detection of disease biomarkers. ACS Nano 2020, 14, 8866-8874. [CrossRef] [PubMed]

33. Kim, B.; Jang, S.; Prabhumirashi, P.L.; Geier, M.L.; Hersam, M.C.; Dodabalapur, A. Low voltage, high performance inkjet printed carbon nanotube transistors with solution processed $\mathrm{ZrO}_{2}$ gate insulator. Appl. Phys. Lett. 2013, 103, 082119. [CrossRef]

34. Kim, B.; Geier, M.L.; Hersam, M.C.; Dodabalapur, A. Inkjet printed circuits based on ambipolar and p-type carbon nanotube thin-film transistors. Sci. Rep. 2017, 7, 39627. [CrossRef]

35. Lin, Y.H.; Pattanasattayavong, P.; Anthopoulos, T.D. Metal-halide perovskite transistors for printed electronics: Challenges and opportunities. Adv. Mater. 2017, 29, 1702838. [CrossRef]

36. Zhu, H.H.; Liu, A.; Noh, Y.Y. Perovskite transistors clean up their act. Nat. Electron. 2020, 3, 662-663. [CrossRef]

37. Yu, W.L.; Li, F.; Yu, L.Y.; Niazi, M.R.; Zou, Y.T.; Corzo, D.; Basu, A.; Ma, C.; Dey, S.; Tietze, M.L.; et al. Single crystal hybrid perovskite field-effect transistors. Nat. Commun. 2018, 9, 5354. [CrossRef] [PubMed]

38. Du, J.Y.; Ge, C.; Riahi, H.; Guo, E.J.; He, M.; Wang, C.; Yang, G.Z.; Jin, K.J. Dual-gated MoS2 transistors for synaptic and programmable logic functions. Adv. Electron. Mater. 2020, 6, 1901408. [CrossRef]

39. Lee, D.H.; Yun, H.J.; Hong, S.; Yoo, H. Ambipolar conduction and multicolor photosensing behaviors from poly(9,9-di-noctylfluorenyl-2,7-diyl)-molybdenum disulfide heterointerfaces. Surf. Interfaces 2021, 27, 101448. [CrossRef]

40. Hong, S.; Choi, S.H.; Park, J.; Yoo, H.; Oh, J.Y.; Hwang, E.; Yoon, D.H.; Kim, S. Sensory adaptation and neuromorphic phototransistors based on $\mathrm{CsPb}\left(\mathrm{Br}_{1-\mathrm{x}} \mathrm{I}_{\mathrm{x}}\right)_{3}$ perovskite and $\mathrm{MoS}_{2}$ hybrid structure. ACS Nano 2020, 14, 9796-9806. [CrossRef]

41. Seo, J.; Yoo, H. Remote doping effects of indium-gallium-zinc oxide thin-film transistors by silane-based self-assembled monolayers. Micromachines 2021, 12, 481. [CrossRef]

42. Stallings, K.; Smith, J.; Chen, Y.; Zeng, L.; Wang, B.; Di Carlo, G.; Bedzyk, M.J.; Facchetti, A.; Marks, T.J. Self-assembled nanodielectrics for solution-processed top-gate amorphous IGZO thin-film transistors. ACS Appl. Mater. Inter. 2021, 13, 15399-15408. [CrossRef] [PubMed]

43. Chu, Y.-L.; Young, S.-J.; Ji, L.-W.; Yan, S.-P. Fabrication and characterization of a-IGZO thin-film transistors with and without passivation layers. ECS J. Solid State Sci. Technol. 2021, 10, 027002. [CrossRef]

44. Park, H.; Yoo, H.; Lee, C.; Kim, J.J.; Im, S.G. Multi-stage organic logic circuits using via-hole-less metal interconnects. IEEE Electron Device Lett. 2020, 41, 1685-1687. [CrossRef]

45. Liu, M.; Wang, H.; Tong, Y.; Zhao, X.; Tang, Q.; Liu, Y. Ultrathin free-substrate n-type PTCDI-C13 transistors with bilayer polymer dielectrics. IEEE Electron Device Lett. 2018, 39, 1183-1186. [CrossRef]

46. Jeong, Y.J.; An, T.K.; Yun, D.-J.; Kim, L.H.; Park, S.; Kim, Y.; Nam, S.; Lee, K.H.; Kim, S.H.; Jang, J.; et al. Photo-patternable ZnO thin films based on cross-linked zinc acrylate for organic/inorganic hybrid complementary inverters. ACS Appl. Mater. Interfaces 2016, 8, 5499-5508. [CrossRef]

47. Jeong, D.Y.; Chang, Y.; Yoon, W.G.; Do, Y.; Jang, J. Low-temperature polysilicon oxide thin-film transistors with coplanar structure using six photomask steps demonstrating high inverter gain of $264 \mathrm{~V} \mathrm{~V}^{-1}$. Adv. Eng. Mater. 2020, 22, 1901497. [CrossRef]

48. Liu, F.; Zhang, Y.; Wang, J.; Chen, Y.; Wang, L.; Wang, G.; Dong, J.; Jiang, C. $\mathrm{MoS}_{2}$ / pentacene hybrid complementary inverter based photodetector with amplified voltage-output. Nanotechnology 2020, 32, 015203. [CrossRef] 
49. Niu, Y.; Gonzalez-Abad, S.; Frisenda, R.; Marauhn, P.; Drüppel, M.; Gant, P.; Schmidt, R.; Taghavi, N.S.; Barcons, D.; Molina-Mendoza, A.J.; et al. Thickness-dependent differential reflectance spectra of monolayer and few-layer $\mathrm{MoS}_{2}, \mathrm{MoSe}_{2}, \mathrm{WS}_{2}$ and WSe 2 . Nanomaterials 2018, 8, 725. [CrossRef]

50. Tosun, M.; Fu, D.; Desai, S.B.; Ko, C.; Seuk Kang, J.; Lien, D.-H.; Najmzadeh, M.; Tongay, S.; Wu, J.; Javey, A. MoS 2 heterojunctions by thickness modulation. Sci. Rep. 2015, 5, 10990. [CrossRef]

51. Zhang, L.; Sharma, A.; Zhu, Y.; Zhang, Y.; Wang, B.; Dong, M.; Nguyen, H.; Wang, Z.; Wen, B.; Cao, Y.; et al. Efficient and layer-dependent exciton pumping across atomically thin organic-inorganic type-I heterostructures. Adv. Mater. 2018, 30 , 1803986. [CrossRef]

52. Ovchinnikov, D.; Allain, A.; Huang, Y.-S.; Dumcenco, D.; Kis, A. Electrical transport properties of single-layer WS 2 . ACS Nano 2014, 8, 8174-8181. [CrossRef]

53. Zhou, H.; Wang, C.; Shaw, J.C.; Cheng, R.; Chen, Y.; Huang, X.; Liu, Y.; Weiss, N.O.; Lin, Z.; Huang, Y.; et al. Large area growth and electrical properties of p-type WSe 2 atomic layers. Nano Lett. 2015, 15, 709-713. [CrossRef] [PubMed]

54. Kim, J.; Jeong, J.; Lee, S.; Jeong, S.; Roh, Y. Analysis of asymmetrical hysteresis phenomena observed in TMD-based field effect transistors. AIP Adv. 2018, 8, 095114. [CrossRef]

55. George, A.; Neumann, C.; Kaiser, D.; Mupparapu, R.; Lehnert, T.; Hübner, U.; Tang, Z.; Winter, A.; Kaiser, U.; Staude, I.; et al. Controlled growth of transition metal dichalcogenide monolayers using Knudsen-type effusion cells for the precursors. J. Phys. Mater. 2019, 2, 016001. [CrossRef]

56. Li, H.; Wu, J.; Yin, Z.; Zhang, H. Preparation and applications of mechanically exfoliated single-layer and multilayer MoS 2 and $\mathrm{WSe}_{2}$ nanosheets. Acc. Chem. Res. 2014, 47, 1067-1075. [CrossRef]

57. Li, H.-M.; Lee, D.-Y.; Choi, M.S.; Qu, D.; Liu, X.; Ra, C.-H.; Yoo, W.J. Metal-semiconductor barrier modulation for high photoresponse in transition metal dichalcogenide field effect transistors. Sci. Rep. 2014, 4, 4041. [CrossRef] [PubMed]

58. George, A.; Fistul, M.V.; Gruenewald, M.; Kaiser, D.; Lehnert, T.; Mupparapu, R.; Neumann, C.; Hübner, U.; Schaal, M.; Masurkar, N.; et al. Giant persistent photoconductivity in monolayer $\mathrm{MoS}_{2}$ field-effect transistors. npj 2D Mater. $2021,5,15$. [CrossRef]

59. Daus, A.; Vaziri, S.; Chen, V.; Köroğlu, Ç.; Grady, R.W.; Bailey, C.S.; Lee, H.R.; Schauble, K.; Brenner, K.; Pop, E. High-performance flexible nanoscale transistors based on transition metal dichalcogenides. Nat. Electron. 2021, 4, 495-501. [CrossRef]

60. Shen, T.; Penumatcha, A.V.; Appenzeller, J. Strain engineering for transition metal dichalcogenides based field effect transistors. ACS Nano 2016, 10, 4712-4718. [CrossRef]

61. Choi, H.J.; Jung, Y.S.; Lee, S.M.; Kang, S.; Seo, D.; Kim, H.; Choi, H.-J.; Lee, G.-H.; Cho, Y.S. Large-scale self-limiting synthesis of monolayer $\mathrm{MoS}_{2}$ via proximity evaporation from Mo films. Cryst. Growth Des. 2020, 20, 2698-2705. [CrossRef]

62. Yu, H.; Liao, M.; Zhao, W.; Liu, G.; Zhou, X.J.; Wei, Z.; Xu, X.; Liu, K.; Hu, Z.; Deng, K.; et al. Wafer-scale growth and transfer of highly-oriented monolayer $\mathrm{MoS}_{2}$ continuous films. ACS Nano 2017, 11, 12001-12007. [CrossRef]

63. Lee, H.S.; Shin, J.M.; Jeon, P.J.; Lee, J.; Kim, J.S.; Hwang, H.C.; Park, E.; Yoon, W.; Ju, S.-Y.; Im, S. Few-layer MoS 2 -Organic thin-film hybrid complementary inverter pixel fabricated on a glass substrate. Small 2015, 11, 2132-2138. [CrossRef] [PubMed]

64. Lee, H.S.; Choi, K.; Kim, J.S.; Yu, S.; Ko, K.R.; Im, S. Coupling two-dimensional MoTe 2 and InGaZnO thin-film materials for hybrid PN junction and CMOS inverters. ACS Appl. Mater. Inter. 2017, 9, 15592-15598. [CrossRef] [PubMed]

65. Das, T.; Chen, X.; Jang, H.; Oh, I.-K.; Kim, H.; Ahn, J.-H. Highly flexible hybrid CMOS inverter based on Si nanomembrane and molybdenum disulfide. Small 2016, 12, 5720-5727. [CrossRef]

66. Allain, A.; Kang, J.; Banerjee, K.; Kis, A. Electrical contacts to two-dimensional semiconductors. Nat. Mater. 2015, 14, 1195-1205. [CrossRef] [PubMed]

67. Liao, W.; Zhao, S.; Li, F.; Wang, C.; Ge, Y.; Wang, H.; Wang, S.; Zhang, H. Interface engineering of two-dimensional transition metal dichalcogenides towards next-generation electronic devices: Recent advances and challenges. Nanoscale Horiz. 2020, 5 , 787-807. [CrossRef] [PubMed]

68. Velický, M.; Toth, P.S. From two-dimensional materials to their heterostructures: An electrochemist's perspective. Appl. Mater. Today 2017, 8, 68-103. [CrossRef]

69. Li, M.; Yao, J.; Wu, X.; Zhang, S.; Xing, B.; Niu, X.; Yan, X.; Yu, Y.; Liu, Y.; Wang, Y. P-type doping in large-area monolayer MoS 2 by chemical vapor deposition. ACS Appl. Mater. Interfaces 2020, 12, 6276-6282. [CrossRef]

70. Jin, Y.; Keum, D.H.; An, S.-J.; Kim, J.; Lee, H.S.; Lee, Y.H. A Van Der Waals Homojunction: Ideal p-n diode behavior in MoSe 2 . Adv. Mater. 2015, 27, 5534-5540. [CrossRef]

71. Liu, J.; Wang, Y.; Xiao, X.; Zhang, K.; Guo, N.; Jia, Y.; Zhou, S.; Wu, Y.; Li, Q.; Xiao, L. Conversion of multi-layered MoTe 2 transistor between P-type and N-type and their use in inverter. Nanoscale Res. Lett. 2018, 13, 291. [CrossRef]

72. Shao, S.; Liang, K.; Li, X.; Zhang, J.; Liu, C.; Cui, Z.; Zhao, J. Large-area $(64 \times 64$ array) inkjet-printed high-performance metal oxide bilayer heterojunction thin film transistors and n-metal-oxide-semiconductor (NMOS) inverters. J. Mater. Sci. Technol. 2021, 81, 26-35. [CrossRef]

73. Li, J.; Song, E.; Chiang, C.-H.; Yu, K.J.; Koo, J.; Du, H.; Zhong, Y.; Hill, M.; Wang, C.; Zhang, J.; et al. Conductively coupled flexible silicon electronic systems for chronic neural electrophysiology. Proc. Natl. Acad. Sci. USA 2018, 115, E9542. [CrossRef] [PubMed]

74. Nomura, K.; Ohta, H.; Takagi, A.; Kamiya, T.; Hirano, M.; Hosono, H. Room-temperature fabrication of transparent flexible thin-film transistors using amorphous oxide semiconductors. Nature 2004, 432, 488-492. [CrossRef] 
75. Sim, K.; Rao, Z.; Zou, Z.; Ershad, F.; Lei, J.; Thukral, A.; Chen, J.; Huang, Q.-A.; Xiao, J.; Yu, C. Metal oxide semiconductor nanomembrane-based soft unnoticeable multifunctional electronics for wearable human-machine interfaces. Sci. Adv. 2019, 5, eaav9653. [CrossRef] [PubMed]

76. Yu, B.-S.; Jeon, J.-Y.; Kang, B.-C.; Lee, W.; Kim, Y.-H.; Ha, T.-J. Wearable 1 V operating thin-film transistors with solution-processed metal-oxide semiconductor and dielectric films fabricated by deep ultra-violet photo annealing at low temperature. Sci. Rep. 2019, 9, 8416. [CrossRef]

77. Kawazoe, H.; Yasukawa, M.; Hyodo, H.; Kurita, M.; Yanagi, H.; Hosono, H. P-type electrical conduction in transparent thin films of $\mathrm{CuAlO}_{2}$. Nature 1997, 389, 939-942. [CrossRef]

78. Wang, Z.; Nayak, P.K.; Caraveo-Frescas, J.A.; Alshareef, H.N. Recent developments in p-type oxide semiconductor materials and devices. Adv. Mater. 2016, 28, 3831-3892. [CrossRef]

79. Hosono, H.; Ueda, K. Transparent conductive oxides. In Springer Handbook of Electronic and Photonic Materials; Kasap, S., Capper, P., Eds.; Springer: Berlin/Heidelberg, Germany, 2017; pp. 1391-1404.

80. Luo, M.; Xie, H.; Wei, M.; Liang, K.; Shao, S.; Zhao, J.; Gao, T.; Mo, L.; Chen, Y.; Chen, S.; et al. High-performance partially printed hybrid CMOS inverters based on indium-zinc-oxide and chirality enriched carbon nanotube thin-film transistors. Adv. Electron. Mater. 2019, 5, 1900034. [CrossRef]

81. Caraveo-Frescas, J.A.; Nayak, P.K.; Al-Jawhari, H.A.; Granato, D.B.; Schwingenschlögl, U.; Alshareef, H.N. Record mobility in transparent p-type tin monoxide films and devices by phase Engineering. ACS Nano 2013, 7, 5160-5167. [CrossRef]

82. Liu, A.; Zhu, H.; Guo, Z.; Meng, Y.; Liu, G.; Fortunato, E.; Martins, R.; Shan, F. Solution combustion synthesis: Low-temperature processing for p-type Cu:NiO thin films for transparent electronics. Adv. Mater. 2017, 29, 1701599. [CrossRef]

83. Honda, W.; Harada, S.; Ishida, S.; Arie, T.; Akita, S.; Takei, K. High-performance, mechanically flexible, and vertically integrated 3D carbon nanotube and InGaZnO complementary circuits with a temperature sensor. Adv. Mater. 2015, 27, 4674-4680. [CrossRef] [PubMed]

84. Lee, S.; Lee, H.S.; Yu, S.; Park, J.H.; Bae, H.; Im, S. Tungsten dichalcogenide nanoflake/InGaZnO thin-film heterojunction for photodetector, inverter, and AC rectifier circuits. Adv. Electron. Mater. 2020, 6, 2000026. [CrossRef]

85. Liu, Z.; Yin, Z.; Chen, S.-C.; Dai, S.; Huang, J.; Zheng, Q. Binary polymer composite dielectrics for flexible low-voltage organic field-effect transistors. Org. Electron. 2018, 53, 205-212. [CrossRef]

86. Sekitani, T.; Nakajima, H.; Maeda, H.; Fukushima, T.; Aida, T.; Hata, K.; Someya, T. Stretchable active-matrix organic light-emitting diode display using printable elastic conductors. Nat. Mater. 2009, 8, 494-499. [CrossRef] [PubMed]

87. Kim, Z.-S.; Lim, S.C.; Kim, S.H.; Yang, Y.S.; Hwang, D.-H. Biotin-functionalized semiconducting polymer in an organic field effect transistor and application as a biosensor. Sensors 2012, 12, 11238-11248. [CrossRef] [PubMed]

88. Wang, Y.; Gong, Q.; Miao, Q. Structured and functionalized organic semiconductors for chemical and biological sensors based on organic field effect transistors. Mater. Chem. Front. 2020, 4, 3505-3520. [CrossRef]

89. Yu, X.; Zhou, N.; Han, S.; Lin, H.; Buchholz, D.B.; Yu, J.; Chang, R.P.H.; Marks, T.J.; Facchetti, A. Flexible spray-coated TIPS-pentacene organic thin-film transistors as ammonia gas sensors. J. Mater. Chem. C 2013, 1, 6532-6535. [CrossRef]

90. Oh, G.; Kim, J.-S.; Jeon, J.H.; Won, E.; Son, J.W.; Lee, D.H.; Kim, C.K.; Jang, J.; Lee, T.; Park, B.H. Graphene/pentacene barristor with Ion-gel gate dielectric: Flexible ambipolar transistor with high mobility and on/off ratio. ACS Nano 2015, 9, 7515-7522. [CrossRef]

91. Tan, L.; Guo, Y.; Zhang, G.; Yang, Y.; Zhang, D.; Yu, G.; Xu, W.; Liu, Y. New air-stable solution-processed organic n-type semiconductors based on sulfur-rich core-expanded naphthalene diimides. J. Mater. Chem. 2011, 21, 18042-18048. [CrossRef]

92. Ye, H.; Kwon, H.-J.; Tang, X.; Lee, D.Y.; Nam, S.; Kim, S.H. Direct patterned zinc-tin-oxide for solution-processed thin-film transistors and complementary inverter through electrohydrodynamic jet printing. Nanomaterials 2020, 10, 1304. [CrossRef] [PubMed]

93. Shi, B.; Liu, B.; Luo, J.; Li, Y.; Zheng, C.; Yao, X.; Fan, L.; Liang, J.; Ding, Y.; Wei, C.; et al. Enhanced light absorption of thin perovskite solar cells using textured substrates. Sol. Energy Mater. Sol. Cells 2017, 168, 214-220. [CrossRef]

94. Cui, D.; Yang, Z.; Yang, D.; Ren, X.; Liu, Y.; Wei, Q.; Fan, H.; Zeng, J.; Liu, S. Color-tuned perovskite films prepared for efficient solar cell applications. J. Phys. Chem. C 2016, 120, 42-47. [CrossRef]

95. Hou, X.; Huang, S.; Ou-Yang, W.; Pan, L.; Sun, Z.; Chen, X. Constructing efficient and stable perovskite solar cells via interconnecting perovskite grains. ACS Appl. Mater. Inter. 2017, 9, 35200-35208. [CrossRef]

96. Zhang, W.; Zhang, F.; Xu, B.; Li, Y.; Wang, L.; Zhang, B.; Guo, Y.; Gardner, J.M.; Sun, L.; Kloo, L. Organic salts as p-type dopants for efficient LiTFSI-free perovskite solar cells. ACS Appl. Mater. Inter. 2020, 12, 33751-33758. [CrossRef]

97. Long, R.; Li, B.; Mi, Q. Selection of contact materials to p-type halide perovskite by electronegativity matching. AIP Adv. 2020, 10, 065224. [CrossRef]

98. Lin, Y.-H.; Huang, W.; Pattanasattayavong, P.; Lim, J.; Li, R.; Sakai, N.; Panidi, J.; Hong, M.J.; Ma, C.; Wei, N.; et al. Deciphering photocarrier dynamics for tuneable high-performance perovskite-organic semiconductor heterojunction phototransistors. Nat. Commun. 2019, 10, 4475. [CrossRef] [PubMed]

99. Zhu, H.; Liu, A.; Shim, K.I.; Hong, J.; Han, J.W.; Noh, Y.-Y. High-performance and reliable lead-free layered-perovskite transistors. Adv. Mater. 2020, 32, 2002717. [CrossRef] [PubMed]

100. Jana, S.; Carlos, E.; Panigrahi, S.; Martins, R.; Fortunato, E. Toward stable solution-processed high-mobility p-type thin film transistors based on halide perovskites. ACS Nano 2020, 14, 14790-14797. [CrossRef] 
101. Zschieschang, U.; Kang, M.J.; Takimiya, K.; Sekitani, T.; Someya, T.; Canzler, T.W.; Werner, A.; Blochwitz-Nimoth, J.; Klauk, H. Flexible low-voltage organic thin-film transistors and circuits based on C10-DNTT. J. Mater. Chem. 2012, 22, 4273-4277. [CrossRef]

102. Zschieschang, U.; Ante, F.; Kälblein, D.; Yamamoto, T.; Takimiya, K.; Kuwabara, H.; Ikeda, M.; Sekitani, T.; Someya, T.; Nimoth, J.B.; et al. Dinaphtho[2,3-b:2', $3^{\prime}$-f]thieno[3,2-b]thiophene (DNTT) thin-film transistors with improved performance and stability. Org. Electron. 2011, 12, 1370-1375. [CrossRef]

103. Acton, O.; Dubey, M.; Weidner, T.; O’Malley, K.M.; Kim, T.-W.; Ting, G.G.; Hutchins, D.; Baio, J.E.; Lovejoy, T.C.; Gage, A.H.; et al. Simultaneous modification of bottom-contact electrode and dielectric surfaces for organic thin-film transistors through single-component spin-cast monolayers. Adv. Funct. Mater. 2011, 21, 1476-1488. [CrossRef]

104. Huang, J.; Somu, S.; Busnaina, A. A molybdenum disulfide/carbon nanotube heterogeneous complementary inverter. Nanotechnology 2012, 23, 335203. [CrossRef]

105. Xu, Q.; Zhao, J.; Pecunia, V.; Xu, W.; Zhou, C.; Dou, J.; Gu, W.; Lin, J.; Mo, L.; Zhao, Y.; et al. Selective conversion from p-type to ntype of printed bottom-gate carbon nanotube thin-film transistors and application in complementary metal-oxide-semiconductor inverters. ACS Appl. Mater. Inter. 2017, 9, 12750-12758. [CrossRef] [PubMed]

106. Wei, M.; Robin, M.; Portilla, L.; Ren, Y.; Shao, S.; Bai, L.; Cao, Y.; Pecunia, V.; Cui, Z.; Zhao, J. Air-stable N-type printed carbon nanotube thin film transistors for CMOS logic circuits. Carbon 2020, 163, 145-153. [CrossRef]

107. Nakashima, Y.; Yamaguchi, R.; Toshimitsu, F.; Matsumoto, M.; Borah, A.; Staykov, A.; Islam, M.S.; Hayami, S.; Fujigaya, T. Air-stable n-type single-walled carbon nanotubes doped with benzimidazole derivatives for thermoelectric conversion and their air-stable mechanism. ACS Appl. Nano Mater. 2019, 2, 4703-4710. [CrossRef]

108. Li, G.; Li, Q.; Jin, Y.; Zhao, Y.; Xiao, X.; Jiang, K.; Wang, J.; Fan, S. Fabrication of air-stable n-type carbon nanotube thin-film transistors on flexible substrates using bilayer dielectrics. Nanoscale 2015, 7, 17693-17701. [CrossRef]

109. Luo, M.; Zhu, M.; Wei, M.; Shao, S.; Robin, M.; Wei, C.; Cui, Z.; Zhao, J.; Zhang, Z. Radiation-hard and repairable complementary metal-oxide-semiconductor circuits integrating n-type indium oxide and p-type carbon nanotube field-effect transistors. ACS Appl. Mater. Inter. 2020, 12, 49963-49970. [CrossRef]

110. Yoon, J.; Jung, H.; Jang, J.T.; Lee, J.; Lee, Y.; Lim, M.; Kim, D.M.; Kim, D.H.; Choi, S.-J. Hybrid complementary inverter based on carbon nanotube and IGZO thin-film transistors with controlled process conditions. J. Alloys Compd. 2018, 762, 456-462. [CrossRef]

111. Hassan, Y.; Srivastava, P.K.; Singh, B.; Abbas, M.S.; Ali, F.; Yoo, W.J.; Lee, C. Phase-engineered molybdenum telluride/black phosphorus Van der Waals heterojunctions for tunable multivalued logic. ACS Appl. Mater. Inter. 2020, 12, 14119-14124. [CrossRef]

112. Panigrahi, D.; Hayakawa, R.; Fuchii, K.; Yamada, Y.; Wakayama, Y. Optically controlled ternary logic circuits based on organic antiambipolar transistors. Adv. Electron. Mater. 2021, 7, 2000940. [CrossRef]

113. Park, C.-J.; Park, H.J.; Kim, J.Y.; Lee, S.-H.; Lee, Y.; Kim, J.; Joo, J. Photo-responsive $\mathrm{MoS}_{2} /$ organic-rubrene heterojunction field-effect-transistor: Application to photo-triggered ternary inverter. Semicond. Sci. Technol. 2020, 35, 065020. [CrossRef]

114. Kim, B. Inkjet-printed ternary inverter circuits with tunable middle logic voltages. Adv. Electron. Mater. 2020, 6, 2000426. [CrossRef]

115. Jeong, J.W.; Choi, Y.-E.; Kim, W.-S.; Park, J.-H.; Kim, S.; Shin, S.; Lee, K.; Chang, J.; Kim, S.-J.; Kim, K.R. Tunnelling-based ternary metal-oxide-semiconductor technology. Nat. Electron. 2019, 2, 307-312. [CrossRef]

116. Kwon, J.; Takeda, Y.; Fukuda, K.; Cho, K.; Tokito, S.; Jung, S. Three-dimensional, inkjet-printed organic transistors and integrated circuits with 100\% yield, high uniformity, and long-term stability. ACS Nano 2016, 10, 10324-10330. [CrossRef] [PubMed]

117. Lyu, R.; Lin, H.; Li, P.; Huang, T. A film-profile-engineered 3-D InGaZnO inverter technology with systematically tunable threshold voltage. IEEE Trans. Electron Devices 2016, 63, 3533-3539. [CrossRef]

118. Park, C.H.; Lee, H.S.; Lee, K.H.; Kim, D.-H.; Kim, H.-R.; Lee, G.-H.; Kim, J.H.; Im, S. Organic/oxide hybrid complementary thin-film transistor inverter in vertical stack for logic, photo-gating, and ferroelectric memory operation. Org. Electron. 2011, 12, 1533-1538. [CrossRef]

119. Rashid, R.B.; Du, W.; Griggs, S.; Maria, I.P.; McCulloch, I.; Rivnay, J. Ambipolar inverters based on cofacial vertical organic electrochemical transistor pairs for biosignal amplification. Sci. Adv. 2021, 7, eabh1055. [CrossRef]

120. Yoo, H.; Park, H.; Yoo, S.; On, S.; Seong, H.; Im, S.G.; Kim, J.-J. Highly stacked 3D organic integrated circuits with via-hole-less multilevel metal interconnects. Nat. Commun. 2019, 10, 2424. [CrossRef]

121. Zhao, Y.; Li, Q.; Xiao, X.; Li, G.; Jin, Y.; Jiang, K.; Wang, J.; Fan, S. Three-dimensional flexible complementary metal-oxidesemiconductor logic circuits based on two-layer stacks of single-walled carbon nanotube networks. ACS Nano 2016, 10, $2193-2202$. [CrossRef]

122. Nomura, K.; Aoki, T.; Nakamura, K.; Kamiya, T.; Nakanishi, T.; Hasegawa, T.; Kimura, M.; Kawase, T.; Hirano, M.; Hosono, H. Three-dimensionally stacked flexible integrated circuit: Amorphous oxide/polymer hybrid complementary inverter using n-type a-In-Ga-Zn-O and p-type poly-(9,9-dioctylfluorene-co-bithiophene) thin-film transistors. Appl. Phys. Lett. 2010, 96, 263509. [CrossRef]

123. Patcharaprakiti, N.; Premrudeepreechacharn, S. Maximum power point tracking using adaptive fuzzy logic control for gridconnected photovoltaic system. In Proceedings of the 2002 IEEE Power Engineering Society Winter Meeting. Conference Proceedings (Cat. No.02CH37309), Columbus, OH, USA, 27-31 January 2002; Volume 371, pp. 372-377. 
124. Lee, J.; Lee, J.; Lee, J.H.; Lee, W.H.; Uhm, M.; Park, B.; Kim, D.M.; Jeong, Y.; Kim, D.H. Complementary silicon nanowire hydrogen Ion sensor with high sensitivity and voltage output. IEEE Electron Device Lett. 2012, 33, 1768-1770. [CrossRef]

125. Cho, C.H.; Choe, Y.-S.; Oh, J.Y.; Lee, T. Il self-assembled 2D networks of metal oxide nanomaterials enabling sub-ppm level breathalyzers. ACS Sens. 2021, 6, 3195-3203. [CrossRef] [PubMed]

126. Jeong, J.; Seo, S.G.; Kim, S.Y.; Jin, S.H. Photosensitive complementary inverters composed of n-channel ReS 2 and p-channel single-walled carbon nanotube field-effect transistors. Phys. Status Solidi RRL 2020, 14, 2000420. [CrossRef]

127. Tsai, J.-H.; Niu, J.-S.; Chen, Y.-C.; Huang, X.-Y. Hydrogen sensing characteristics of AlGaInP/InGaAs complementary Cointegrated pseudomorphic doping-channel field-effect transistors. ECS J. Solid State Sci. Technol. 2018, 7, Q191-Q195. [CrossRef]

128. Rashid, R.B.; Ji, X.; Rivnay, J. Organic electrochemical transistors in bioelectronic circuits. Biosens. Bioelectron. 2021, 190, 113461. [CrossRef] [PubMed]

129. Kim, J.-H.; Bang, J.W.; Seo, S. Organic photovoltaic application for new insights into bio-analytic systems. Sci. Adv. Mater. 2016, 8 , 47-51. [CrossRef]

130. Baek, S.; Kwon, J.; Mano, T.; Tokito, S.; Jung, S. A flexible 3D organic preamplifier for a lactate sensor. Macromol. Biosci. 2020, 20, 2000144. [CrossRef] 